\title{
Numerical modelling of intra-wave sediment transport on sandy beaches using a non-hydrostatic, wave-resolving model
}

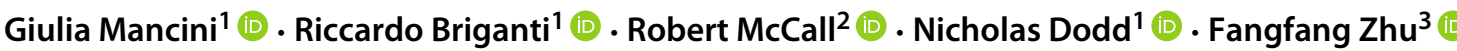

Received: 27 December 2019 / Accepted: 28 September 2020 / Published online: 23 November 2020

(C) The Author(s) 2020

\begin{abstract}
The mutual feedback between the swash zone and the surf zone is known to affect large-scale morphodynamic processes such as breaker bar migration on sandy beaches. To fully resolve this feedback in a process-based manner, the morphodynamics in the swash zone and due to swash-swash interactions must be explicitly solved, e.g., by means of a wave-resolving numerical model. Currently, few existing models are able to fully resolve the complex morphodynamics in the swash zone, and none is practically applicable for engineering purposes. This work aims at improving the numerical modelling of the intra-wave sediment transport on sandy beaches in an open-source wave-resolving hydro-morphodynamic framework (e.g., non-hydrostatic XBeach). A transport equation for the intra-wave suspended sediment concentration, including an erosion and a deposition rate, is newly implemented in the model. Two laboratory experiments involving isolated waves and wave trains are simulated to analyse the performance of the model. Numerical results show overall better performance in simulating single waves rather than wave trains. For the latter, the modelling of the morphodynamic response improves in the swash zone compared with the existing sediment transport modelling approach within non-hydrostatic XBeach, while the need of including additional physical processes to better capture sediment transport and bed evolution in the surf zone is highlighted in the paper.
\end{abstract}

Keywords Wave-resolving modelling · Hydro-morphodynamics modelling · Intra-wave sediment transport . Suspended sediment concentration $\cdot$ Swash zone

\section{Introduction}

Sandy beach evolution plays a key role in coastal vulnerability, influencing the stability of ecosystems and coastal communities' economy and safety. Their morphodynamical evolution and response to drivers such as increased storminess remain difficult to predict (Wong et al. 2014).

The exchange of sediments between the swash zone and the surf zone determines the evolution of the beach

Responsible Editor: Bruno Castelle

Giulia Mancini

giulia.mancini1@nottingham.ac.uk

1 Department of Civil Engineering, University of Nottingham, Nottingham NG7 2RD, UK

2 Deltares, Department of Applied Morphodynamics, 2629 HV, Delft, The Netherlands

3 Department of Civil Engineering, University of Nottingham, Taikang East Road, Ningbo, 315100, China and shoreface (Masselink and Puleo 2006; Brocchini and Baldock 2008; Alsina et al. 2012; Masselink and Gehrels 2014). These two regions behave as interacting and coevolving morphodynamic subsystems. Consequently, it is difficult to separate the contributions of the surf zone and swash zone to the development and migration of breaker bars. Moreover, swash-swash interactions present in wave trains can affect the offshore-directed sediment transport that feeds the migration of bars (Alsina et al. 2012).

Wave-resolving hydro-morphodynamic models are needed to provide an accurate description of these complex dynamics because they include intra-wave physical processes, which make these models suitable to fully solve swash morphodynamics. The models of this type in the literature use as governing hydrodynamic equations one of the following alternatives: the Non-Linear Shallow Water Equations (NLSWE) (e.g., Li et al. 2002, Postacchini et al. 2012, Zhu and Dodd 2015, Incelli et al. 2016, see Briganti et al. 2016 for a review), the non-hydrostatic NLSWE (e.g., Smit et al. 2010, Ma et al. 2012, Ruffini et al. 2020), or Boussinesq-type equations (e.g., Xiao et al. 2010, Wenneker 
et al. 2011, Kim et al. 2017). While hydrostatic NLSWE do not allow frequency dispersion, thus limiting their application, the other two aforementioned sets of flow equations are widely used for wave propagation from intermediate waters to the shoreline. The non-hydrostatic NLSWE are used in the open-source Non-Hydrostatic version of the XBeach (XBNH) model (Smit et al. 2010; Roelvink et al. 2018). To enable the computation of morphodynamics, these models would require sub-models that compute suspended and bed load sediment transport based on intra-wave hydrodynamics, from which in turn bed level change can be computed.

In the framework of non-hydrostatic NLSWE, formulations of sediment transport have been extensively tested for gravel beaches (e.g., McCall et al. 2015), but not for sandy beaches. Ruffini et al. (2020) showed that application of a wave-averaged sediment transport equation (Van Thiel de Vries 2008; Van Rijn 2007) in XBNH led to inaccurate simulated beach morphodynamics, which was related to inaccuracies in modelled sediment concentrations, particularly during flow reversal.

The aim of this work is to improve the modelling of intra-wave sediment dynamics in XBNH. To this end, the Pritchard and Hogg (2003) and Meyer-Peter and Müller (1948) formulations are chosen because of their good performance in the swash zone (see Zhu and Dodd 2015). The present study focuses on modelling the dynamics of sediment in the nearshore zone in all stages of the flow both for solitary waves, i.e., isolated waves, and wave trains, with significant swash-swash interactions. First, the proposed hydro-morphodynamic model is verified against a high-resolution numerical solution of an idealised bore generated by a solitary wave over an erodible sloped beach. Subsequently, two experimental case studies are simulated involving bichromatic wave groups and consecutive noninteracting solitary waves over sandy beaches. For the former, a sensitivity analysis of the results to the parameters used in the Pritchard and Hogg (2003) sediment transport equation is also carried out.

This paper is organised as follows: $\mathrm{XBNH}$, with a focus on the sediment transport and bed-updating modelling, is described in Section 2; verification of the proposed model is illustrated in Section 3; the performance of the model against two laboratory experiments is presented in Sections 4 and 5, respectively; discussion of results and concluding remarks with recommendations for future works are given in Sections 6 and 7, respectively.

\section{Model description}

XBNH consists of coupled wave-resolving hydrodynamics and morphodynamics equations. The existing approach for suspended and bed load transport in XBNH were originally developed for the Wave-Averaged Sediment Transport (WAST) modelling (see Appendix 1). Therefore, in the present work, a wave-resolving formulation for the suspended sediment transport is implemented in the model. To this end, the transport advection equation of Pritchard and Hogg (2003) is chosen. XBNH computes the bed load transport using the Meyer-Peter and Müller (1948) expression. The combined use of the newly implemented Pritchard and Hogg (2003) equation with the Meyer-Peter and Müller (1948) formula within XBNH for the Intra-Wave Sediment Transport (IWST) modelling is herein referred as XBNH-IWST. In this work, only the cross-shore direction is considered; Fig. 1 shows a schematisation of a typical cross-shore profile with the main variables used.

The model performance is quantified by computing the normalised Root-Mean-Square Error (nRMSE), defined as:

$n R M S E=\frac{\sqrt{\frac{1}{N} \Sigma_{i}^{N}\left(y_{m, i}-y_{r e f, i}\right)^{2}}}{s_{y_{r e f}}}$,

where $y_{m, i}$ is the $i$-th sample of the modelled quantity $y$, and $y_{r e f, i}$ is the $i$-th sample of the corresponding reference variable (e.g., semi-analytical, experimental); $N$ is the number of samples; $s_{y_{r e f}}$ is the standard deviation of the reference quantity, $y_{r e f}$, and it is defined as:

$s_{y_{r e f}}=\sqrt{\frac{1}{N-1} \Sigma_{i}^{N}\left(y_{r e f, i}-\bar{y}_{r e f}\right)^{2}}$,

with $\bar{y}_{r e f}=(1 / N) \Sigma_{i}^{N} y_{r e f, i}$ being the mean value of $y_{\text {ref }}$. nRMSE $=0$ indicates perfect agreement between model predictions and reference quantities, whereas nRMSE $=1$ indicates that the Root-Mean-Square Error (RMSE) equals $s_{y_{\text {ref }}}$.

Following Bosboom et al. (2020), the Root-Mean-Square Transport Error (RMSTE) is also computed to quantify the model performance in terms of final bed changes. The RMSTE $\left(\mathrm{m}^{2}\right)$ measures the mismatch between the predicted final bed level, $z_{b_{f, m}}$, and the reference one, $z_{b_{f, r e f}}$, in terms of the minimum (i.e., optimal) quadratic sediment transport cost required to transform the predictions into the reference field, and it is computed as:

$R M S T E=\sqrt{\frac{1}{N} \Sigma_{i}^{N} Q_{i}^{2}}$,

where $Q_{i}$ is $i$-th sample along the cross-shore coordinate, $x$, of the sediment volume, $Q$, required to transform $z_{f, m}$ into $z_{b_{f, r e f}}$. The conservation of mass is satisfied so that $\partial Q / \partial x=z_{b_{f, m}}-z_{b_{f, r e f}}$ and $Q_{i=1}=0$ is assumed (with $i=1$ referring to the onshore boundary of the $x$ - domain, located landward of the maximum run up). 
To further assess the correlation between time series of modelled and reference quantities, Pearson's cross-correlation coefficient, $-1 \leq \rho_{m r} \leq 1$, is used and it is defined as:

$\rho_{m r}=\frac{\operatorname{cov}\left(y_{r e f}, y_{m}\right)}{s_{y_{r e f}} s_{y_{m}}}$,

where $\operatorname{cov}\left(y_{\text {ref }}, y_{m}\right)$ is the covariance of the time series of modelled and reference quantities and it is computed as:

$\operatorname{cov}\left(y_{m, i}, y_{r e f, i}\right)=\frac{1}{(N-1)} \Sigma_{i}^{N}\left(y_{m, i}-\bar{y}_{m}\right)\left(y_{r e f, i}-\bar{y}_{r e f}\right)$,

where $\bar{y}_{m}=(1 / N) \Sigma_{i}^{N} y_{m, i}$ is the mean value of $y_{m}$, and $s_{y_{m}}$ is the standard deviation of the time series of the predicted quantity.

\subsection{Hydrodynamics}

The hydrodynamics in $\mathrm{XBNH}$ is similar to the one-layer version of SWASH (Zijlema et al. 2011). The depthaveraged flow is computed using the non-hydrostatic 1D (one-dimensional) NLSWE:

$\frac{\partial \eta}{\partial t}+\frac{\partial h u}{\partial x}=0$

$\frac{\partial u}{\partial t}+u \frac{\partial u}{\partial x}-\frac{\partial}{\partial x}\left(v_{h} \frac{\partial u}{\partial x}\right)=-\frac{1}{\rho} \frac{\partial\left(\rho p_{n h}+\rho g \eta\right)}{\partial x}-\frac{\tau_{b}}{h}$,

where $t$ is time, $\eta$ is the water surface elevation from the Still Water Level (SWL), $u$ is the depth-averaged crossshore velocity, $h$ is the total water depth, $v_{h}$ is the horizontal viscosity, $\rho$ is the density of water, $p_{n h}$ is the depth-averaged dynamic pressure normalised by the density, $g$ is the gravity acceleration constant and $\tau_{b}$ is the total bed shear stress, which is computed as:

$\tau_{b}=\rho c_{f} u|u|$,

where $c_{f}$ is the dimensionless friction coefficient. Relatively simple unsteady Bottom Boundary Layer (BBL) models, such as the momentum integral method (Sumer et al. 1987) used also in NLSWE solvers (e.g., Briganti et al. 2011), could be considered. However, the results in terms of $\tau_{b}$ are comparable with simpler formulations, such as the one considered in this study (see e.g., Briganti et al. 2018). Also, phase differences could be significant and more complex BBL models should be used (e.g., Rijnsdorp et al. 2017). Nevertheless, the detailed modelling of the BBL is outside the scope of the present work.

$p_{n h}$ allows to account for wave dispersion with similar accuracy to that of weakly non-linear Boussinesq-type models (Bai et al. 2018). In the cases analysed in this study, the dispersivity parameter, $k_{w} d$ is lower than 0.5 , where $k_{w}$ is the wave number (defined as $k_{w}=2 \pi / L$, with $L$ being the local wave length) and $d$ is the still water depth (see
Fig. 1). Therefore, the celerity error in the description of frequency dispersion is of the order of $1 \%$ (Bai et al. 2018).

Wave breaking in $\mathrm{XBNH}$ is modelled by using the Hydrostatic Front Approximation (HFA) of Smit et al. (2013), in which the non-hydrostatic pressure term is set to 0 when $\frac{\partial \eta}{\partial t}>0.4 c$ (with $c=\sqrt{g h}$ the wave celerity in shallow water). After this condition is reached, waves propagate as hydrostatic bores. The reader is referred to Smit et al. (2010) and McCall (2015) for a full description of the XBNH model.

\subsection{Intra-wave sediment transport modelling}

In this study, the Pritchard and Hogg (2003) advection equation for the intra-wave suspended sediment transport is included in $\mathrm{XBNH}$ :

$\frac{\partial h C}{\partial t}+\frac{\partial h u C S_{s l}}{\partial x}=m_{e}\left(\frac{\tau_{b}-\tau_{b, c r}}{\tau_{r e f}}\right)^{R}-w_{s} C_{n b}=E-D$,

where $C$ is the depth-averaged suspended sediment concentration; its maximal value, $C_{\text {max }}$, is herein considered the higher physically possible sediment concentration for a fluidised bed and defined as $C_{\max }=1-n_{p, d}$, with $n_{p, d}=0.6$, the porosity for a fluidised bed; $S_{s l}$ represents the bed slope effects computed following Deltares (2015):

$S_{s l}=1-\alpha_{s l} \frac{\partial z_{b}}{\partial x}$,

where $\alpha_{s l}=1.6$ according to Deltares (2015) and $z_{b}$ is the bed level. Therefore, the suspended sediment transport rate, $q_{s}$, is defined as $q_{s}=h u C S_{s l} \cdot m_{e}$ is the mobility parameter, which determines the erodibility of the sediment as suspended load, $\tau_{b, c r}$ is the critical bed shear stress, $\tau_{r e f}$ is the reference bed shear stress, $R>0$ is a dimensionless exponent (Pritchard and Hogg 2003), $w_{s}$ is the sediment settling velocity and $C_{n b}$ is the near-bed suspended sediment concentration at a small near-bed reference height, $d_{n b}$, above $z_{b}$. The two terms on the right side in Eq. (9) represent the erosion rate, $E$, and the deposition rate, $D$, respectively. $C_{n b}$ in $D$ is computed as:

$C_{n b}=C K_{C}$,

where the shape factor, $K_{C}$, represents the relative importance of sediment settling and mixing. When good mixing is assumed $K_{C}=1$. Since the suspension is assumed to be sufficiently diluted, there is no feedback between the suspended sediment and the vertical distribution of turbulence. Therefore, $K_{C}$ depends only on sediment properties and the depth-averaged hydrodynamics. Consequently:

$K_{C}=\frac{(1-B)}{d_{n b}^{\prime}\left(d_{n b}^{\prime B-1}-1\right)}$, 
Fig. 1 Schematisation of cross-shore profile and main variables considered, which are explained in the text

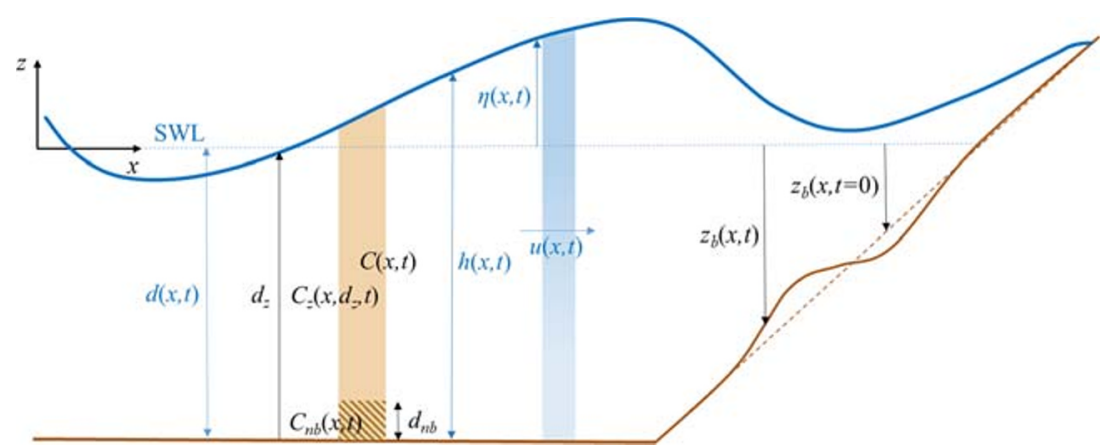

where $B$ is the Rouse number defined as:

$B=\frac{w_{s}}{\kappa u_{*}}$,

where $\kappa=0.4$ is the von Karman constant and $u_{*}$ is the friction velocity: $u_{*}=\left(\tau_{b} / \rho\right)^{1 / 2} \cdot d_{n b}^{\prime}$ is the dimensionless near-bed reference height, given by a simplified form of Van Rijn formula as shown in Soulsby (1997) with the relationship:

$d_{n b}^{\prime}=\frac{d_{n b}}{h}=0.519\left(\frac{D_{50}}{\lambda}\right)^{0.3}$,

in which $D_{50}$ is the median grain diameter, and $\lambda$ is a reference length scale.

The model described above allows expressing the vertical distribution of suspended sediment by a power-law profile as in Soulsby (1997):

$C_{z}\left(d_{z}\right)=C_{n b}\left(\frac{d_{z}}{d_{n b}}\right)^{-B} \quad$ in which $\quad d_{n b} \leq d_{z} \leq h$,

where $d_{z}$ is the vertical elevation from $z_{b}$ (see Fig. 1). The concentration profile described by Eq. (15) corresponds to a linearly increasing eddy diffusivity of the sediment with the height above the bed. Note that $C_{z}$ is not a model output, but it is herein computed in the aftermath of the numerical simulations.

The bed load transport rate, $q_{b}$, is calculated using the equation derived by Meyer-Peter and Müller (1948). The reader is referred to McCall (2015) for the existing implementation of this formula in $\mathrm{XBNH}$, and it is summarised here, following with the main equation:

$q_{b}=8\left(\theta-\theta_{c r}\right)^{1.5} \sqrt{\Delta g D_{50}^{3}} \frac{\tau_{b}}{\left|\tau_{b}\right|} S_{s l}$,

where $\theta$ and $\theta_{c r}$ are the Shields and critical Shields parameters, respectively; $\Delta=\left(\rho_{s}-\rho\right) / \rho$, in which $\rho_{s}$ is the sediment density. $\theta$ is computed as $\theta=\tau_{b} /\left(\Delta \rho g D_{50}\right)$, and $\theta_{c r}$ is given by Soulsby (1997).
The Meyer-Peter and Müller (1948) formula is considered appropriate for the swash zone according to previous studies (see Chardón-Maldonado et al. 2016 among others) and variations of the formula have been tested, for example in Postacchini et al. (2012) for sand and Briganti et al. (2018) for coarse sand. When compared with the original Meyer-Peter and Müller (1948) formula, the Postacchini et al. (2012) formulation showed very similar results in terms of net bed changes (see Briganti et al. 2016). Therefore, in this study we did not test other formulas because of the limited differences in the swash zone shown in the literature.

\subsection{Bed-updating modelling}

The bed-updating is modelled using the Exner-type equation:

$\left(1-n_{p}\right) \frac{\partial z_{b}}{\partial t}+E-D+\frac{\partial q_{b}}{\partial x}=0$,

where $n_{p}$ is the bed porosity; $E$ and $D$ are formulated as shown in Eq. (9), and $q_{b}$ is computed as in Eq. (16).

\subsection{Numerical scheme}

$\mathrm{XBNH}$ uses a staggered grid where depth, water level and sediment concentration are defined in the cells centres, and velocity and sediment flux at the cells interfaces. The hydrodynamic equations are solved by applying a limited version of the McCormack (1969) predictor-corrector scheme, which is second-order accurate where the solution is smooth and reduces to first-order accuracy in proximity of discontinuities. The method is mass and momentum conservative (Smit et al. 2010).

For the sediment transport and bed-updating modelling, a finite volume approach is applied, where upwind approximations are used (Deltares 2015). XBNH uses a dynamically adjusted time step. Thus, a value for the maximum Courant Number, $\mathrm{CN}$, is defined and the program in turn adjusts the time step, $\Delta t$, in order to guarantee that $u \Delta t / \Delta x<\mathrm{CN}$, where $\Delta x$ is the computational grid size. In this study, $\mathrm{CN}=0.7$ was used. 


\section{Model verification}

In this section, the performance of the hydro-morphodynamic model proposed in this study is verified against the highresolution numerical solution obtained by Zhu and Dodd (2015), in which an idealised bore generated by a solitary wave over an erodible sloped beach was simulated.

\subsection{Zhu and Dodd (2015) model set-up}

Figure 2 shows the model domain in Zhu and Dodd (2015). In the region $x<-10 \mathrm{~m}$ the bed is flat, while for $x \geq-10 \mathrm{~m}$ an erodible 1:15 sloped beach is considered. The initial shoreline position is located at $x=5 \mathrm{~m}$. The initial conditions of $\eta$ and $u$ along the cross-shore direction were given by Mei (1989) and the hydrodynamic Riemann condition, respectively. As shown in Fig. 2, at the initial condition, the wave crest is located at $x=-22 \mathrm{~m}$. The wave height, $H$, is equal to $0.60 \mathrm{~m}$. The governing equations in Zhu and Dodd (2015) were solved using the Method Of Characteristics (MOC), and the hydrodynamics were solved using the hydrostatic NLSWE, which included bed shear stress. The suspended sediment transport was computed using the Pritchard and Hogg (2003) transport equation, assuming a well-mixed condition (i.e., $K_{C}=1$ ). The bed load was given by the Meyer-Peter and Müller (1948) formula.

\subsection{Model set-up and parameters}

The model set-up and physical parameters followed closely those used in Zhu and Dodd (2015). Time series of $\eta$ and $u$ were provided by Zhu and Dodd (2015) at $x_{0}=-20$ $\mathrm{m}$, i.e., where the wave does not propagate as a bore. Thus, as shown in Fig. 2, the upstream boundary in the model domain is located at $x_{0}$; the computational domain extended to $x=25 \mathrm{~m} . \Delta x=0.05 \mathrm{~m}$ was chosen. The simulated

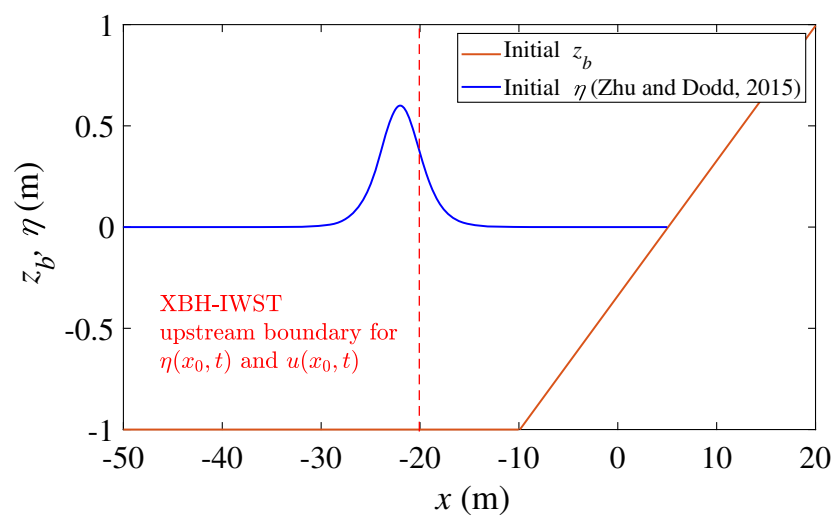

Fig. 2 Model domain and initial condition in Zhu and Dodd (2015) and upstream boundary location in XBH-IWST model domain (reddashed line) time was approximately $33 \mathrm{~s}$. Table 1 shows a summary of the main parameters included and conditions assumed in the Pritchard and Hogg (2003) equation. Similarly to Zhu and Dodd (2015), the well-mixed condition was assumed (i.e., $K_{C}=1$ was set). Consistently with the cited study, bed slope effects in the computation of $q_{s}$ and $q_{b}$ were not taken into account. To compare the response of the model proposed in this study with Zhu and Dodd (2015) in terms of intra-wave sediment transport, the hydrostatic approach was considered by turning off the non-hydrostatic pressure term. This model configuration is herein referred to as XBH-IWST.

\subsection{Comparison between model predictions and Zhu and Dodd (2015)}

Comparison of model predictions with Zhu and Dodd (2015) for the hydrodynamics is shown in Appendix 2; here, only the modelling of beach morphodynamics is discussed.

Figure 3 shows the final bed profiles, $z_{b_{f}}(\mathbf{a})$, and the final bed changes, $\Delta z_{b_{f}}=z_{b}\left(t=t_{f}, x\right)-z_{b}(0, x)(\mathbf{b}) ; t_{f}$ is the time at the end of the simulation. Despite the height of the bed step being underestimated by $20 \%$ with respect to Zhu and Dodd (2015), XBH-IWST captures the erosion and deposition well. nRMSE $=0.0085$ for $\Delta z_{b_{f}}$ and RMSTE $=0.003 \mathrm{~m}^{2}$, showing good performances of XBH-IWST in simulating the solution of Zhu and Dodd (2015). Similarly to Briganti et al. (2012), $\Delta z_{b_{f}}$ was post-processed by using a moving average. Spurious oscillations are shown in the region $x>2 \mathrm{~m}$ during the backwash bore, which runs down the beach and generates a sharp deposition at $x \simeq$ $2 \mathrm{~m}$. Note that Zhu and Dodd (2015) used a shock-fitting scheme. Increasing $\Delta x$ by an order of magnitude reduces the oscillations; however, as expected, it was found that the much lower resolution would lead to the underestimation of the height of the backwash step by $50 \%$. While not being the aim of this study, the implementation of a shock-capturing numerical scheme could help overcome this issue.

Table 1 Main parameters and conditions in the Pritchard and Hogg (2003) transport equation

Pritchard and Hogg (2003) equation

$\begin{aligned} c_{f} & =0.01 \\ w_{s} & =0.03 \mathrm{~m} / \mathrm{s} \\ m_{e} & =0.002 \mathrm{~m} / \mathrm{s} \\ \tau_{b, c r} & =0 \mathrm{~N} / \mathrm{m}^{2} \\ \lambda & =1 \mathrm{~m} \\ \tau_{r e f} & =\rho c_{f} u_{r e f}\left|u_{r e f}\right|, \text { where } u_{r e f}=\sqrt{g \lambda} \\ R & =1 \\ K_{C} & =1 \text { (set constant in XBH-IWST; assumption of well-mixing) }\end{aligned}$


a

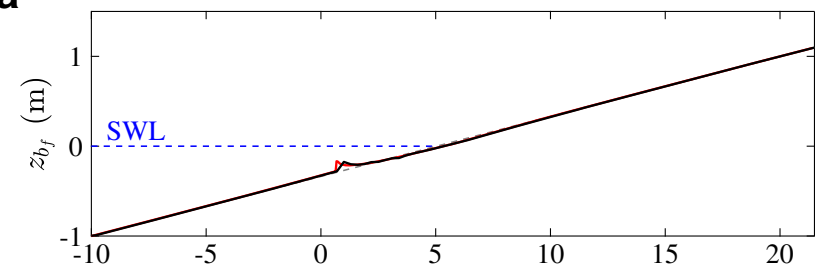

b

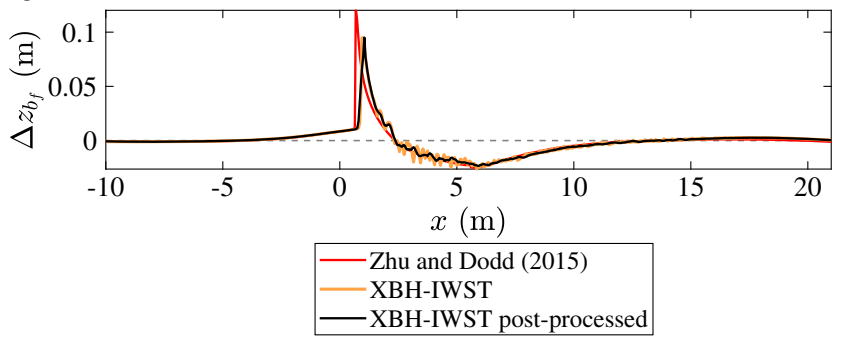

Fig. $3 z_{b_{f}}$ a and $\Delta z_{b_{f}} \mathbf{b}$; reference line: grey-dashed line

Figure 4 shows the time series of $C$ at two different locations along $x$. The corresponding nRMSE are 0.2142 $(x=0 \mathrm{~m})$ and $0.3200(x=5 \mathrm{~m})$. The high correlation between the predicted $C$ and that computed by Zhu and Dodd (2015) is confirmed by $\rho_{m r}=0.9922(x=0 \mathrm{~m})$ and $\rho_{m r}=0.9877(x=5 \mathrm{~m})$.

\section{Numerical modelling of bichromatic wave groups on an intermediate beach}

In this section, the performance of XBNH-IWST is assessed against the experiments conducted within the Hydralab IV

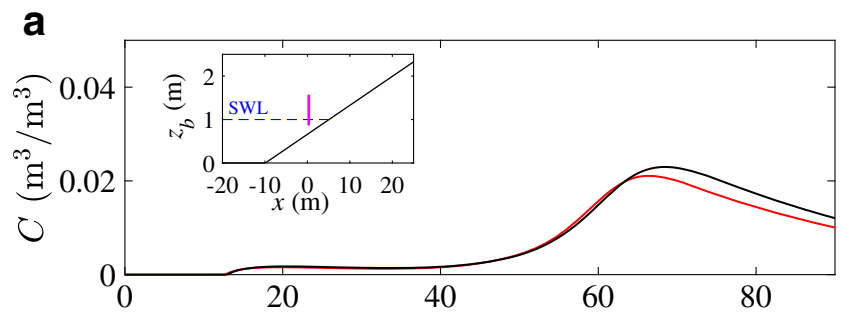

b

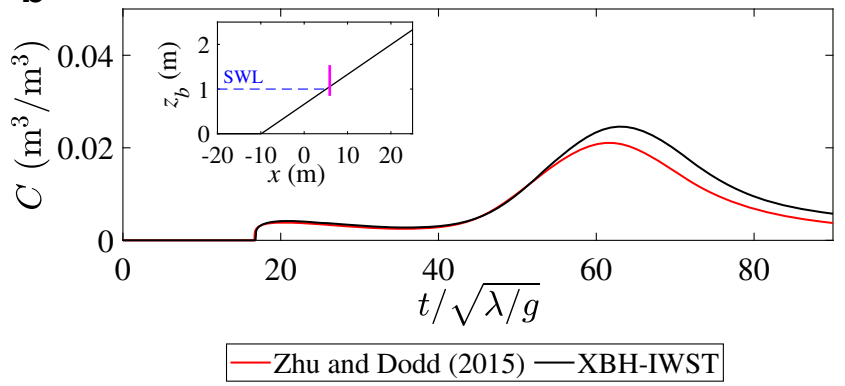

Fig. 4 Time series of $C$ at $x=0 \mathrm{~m}$ a and $x=5 \mathrm{~m} \mathrm{~b}$; the two subplots in $\mathbf{a}$ and $\mathbf{b}$ show the two cross-shore locations in the model domain, respectively
- CoSSedM (Coupled High Frequency Measurement of Swash Sediment Transport and Morphodynamics) project (see Alsina et al. 2016). The experiments studied the hydromorphodynamics of bichromatic wave groups on a 1:15 sloped beach built at prototype scale with commercial sand characterised by $D_{50}=0.25 \mathrm{~mm}, w_{s}=0.034 \mathrm{~m} / \mathrm{s}$ and $n_{p}=$ 0.36 , which showed clearly swash-swash interactions.

Two bichromatic wave group conditions with the same energy content were generated in the flume: BE1_2 (broadbanded wave condition) and BE4_2 (narrow-banded wave condition), respectively, with varying wave group period, $T_{g}$, and repeat period, $T_{r}$. For BE1 $1_{-} 2, T_{g}=15 \mathrm{~s}$ and $T_{r}=$ $195 \mathrm{~s}$, whereas for BE4_2, $T_{g}=T_{r}=27.7 \mathrm{~s}$ (see also Alsina et al. 2018). $T_{g}=1 / f_{g}$, where $f_{g}$ is the group frequency, which is defined as the difference of the primary frequencies, $f_{1}$ and $f_{2}$. A summary of the bichromatic wave groups is shown in Table 2, where $H_{1}$ and $H_{2}$ are the wave heights of the primary components.

For each wave condition, starting from the same initial $z_{b}$ (1:15 uniform sloped bed), eight successive bichromatic wave sequences, from SEG1 to SEG8, each of $1800 \mathrm{~s}$ duration, were generated. Figure 5 shows the initial $z_{b}$ and the location of the instruments in the wave flume and selected for comparison. Wave Gauges (WG) and Acoustic Wave Gauges (AWG) measured $\eta$; Acoustic Doppler Velocimeters (ADV) measured the local flow velocity. Optical Back-Scattering sensors (OBS) and Conductivity Concentration Measurements $\left(\mathrm{CCM}^{+}\right)$tanks measured $C_{z}$ and time-dependent $z_{b}$ in the swash zone, respectively. $d$ in the horizontal part of the domain was $2.48 \mathrm{~m}$ for BE1_2 and $2.46 \mathrm{~m}$ for BE4_2.

The beach is classified using the dimensionless settling velocity, $\Omega$, defined as Gourlay and Meulen (1968): $\Omega=$ $H_{r m s} /\left(w_{s} T_{p}\right)$, where $H_{r m s}$ is the root-mean-square wave height computed at WG3 (i.e., $H_{r m s}=0.39 \mathrm{~m}$ for BE1_2 and $H_{r m s}=0.40 \mathrm{~m}$ for BE4_2) and $\left.T_{p}=1 /\left(f_{1}+f_{2}\right) / 2\right)=$ $3.70 \mathrm{~s}$ is the mean primary wave period for both wave conditions. It is computed that $1<\Omega<6$, which indicates an intermediate beach.

The reader is referred to Alsina et al. (2016) for a detailed description of the experimental procedure.

Table 2 Bichromatic wave groups for wave conditions BE1_2 and BE4_2

\begin{tabular}{lll}
\hline & BE1_2 & BE4_2 \\
\hline$f_{1}(\mathrm{~Hz})$ & 0.303 & 0.288 \\
$H_{1}(\mathrm{~m})$ & 0.30 & 0.28 \\
$f_{2}(\mathrm{~Hz})$ & 0.237 & 0.252 \\
$H_{2}(\mathrm{~m})$ & 0.26 & 0.30 \\
$f_{g}(\mathrm{~m})$ & 0.067 & 0.036 \\
\hline
\end{tabular}




\subsection{Model set-up and parameters}

The model domain is the same as Ruffini et al. (2020). As shown in Fig. 5, the upstream boundary in the model is located at $x_{0}=30.55 \mathrm{~m}$, where the WG3 was installed. Thus, the model domain extended from WG3 to the end of the beach, located at $x=85.05 \mathrm{~m}$, and like the cited study $\Delta x=0.1 \mathrm{~m}$. Time series of $\eta$ and $u$, updated as offshore forcing, were the same as those used in Ruffini et al. (2020) as boundary conditions. For the computation of $c_{f}$, a slightly lower value of the Manning coefficient, $n$, than in Ruffini et al. (2020) was used. $n=0.018 \mathrm{~s} / \mathrm{m}^{1 / 3}$ was calibrated considering the best compromise between the accuracy of maximum run-up and morphological evolution. The value chosen still reflects the characteristics of the considered sandy beach. Model parameters, which are not mentioned herein, were set to their default values defined in Deltares (2015).

The calibration of the sediment transport model in XBNH-IWST was carried out by varying $m_{e}, R$ and $\lambda$. Table 3 summarises the main parameters included and conditions assumed in the Pritchard and Hogg (2003) transport equation. This set of parameters was chosen as it provided the best modelling in the sensitivity analysis shown in Section 4.2.

Only the first two segments, SEG1 and SEG2, were simulated for both BE1_2 and BE4_2 because those segments showed larger morphological changes than the subsequent ones. For BE1_2, the experimental bed evolution reached an equilibrium more rapidly compared with BE4_2. However, SEG1 and SEG2 were far from equilibrium for both cases.

\subsection{Sensitivity analysis for the Pritchard and Hogg (2003) transport equation}

The sensitivity analysis of the results to the parameters used in the Pritchard and Hogg (2003) transport equation was carried out for SEG1 of BE1_2 wave condition. The aim of the sensitivity analysis is to show the relative effects of these parameters in terms of the modelled $C$ and $\Delta z_{b_{f}}=$

Table 3 Main parameters and conditions in the Pritchard and Hogg (2003) transport equation

Pritchard and Hogg (2003) equation

$\begin{array}{ll}m_{e} & =0.01 \mathrm{~m} / \mathrm{s} \\ \tau_{b, c r} & =0 \mathrm{~N} / \mathrm{m}^{2} \\ \lambda & =\text { Considered wave height at the upstream boundary } \\ \tau_{r e f} & =\rho c_{f, r e f} u_{r e f}\left|u_{r e f}\right|, \text { where } c_{f, r e f}=g n^{2} / \lambda^{1 / 3} \text { and } u_{r e f}=\sqrt{g \lambda} \\ R \quad & 1.5 \\ K_{C} & \geq 1(\text { computed by XBNH-IWST) }\end{array}$

$z_{b}\left(t=t_{f}, x\right)-z_{b}(0, x) ; t_{f}$ is the time at the end of SEG1. The parameters considered are $m_{e}, R$ and $\lambda$. Note that $\lambda$ also affects $\tau_{\text {ref }}$ (see Table 3 ) and $K_{C}$ following Eqs. (12) and (14). According to Zhu and Dodd (2015), $\tau_{b, c r}$ is not analysed because the effect of a threshold for suspended load is negligible for fine sand; hence, $\tau_{b, c r}=0 \mathrm{~N} / \mathrm{m}^{2}$.

Each parameter is varied by keeping the others to their reference values as in Zhu and Dodd (2015) (i.e., $m_{e}=$ $0.002 \mathrm{~m} / \mathrm{s}, \lambda=1 \mathrm{~m}$ and $R=1) . m_{e}$ is the least welldetermined parameter, due to the lack of data to provide its estimates. Since $m_{e}=0.002 \mathrm{~m} / \mathrm{s}$ is found to underestimate both $\Delta z_{b_{f}}$ and $C$, the sensitivity analysis for $m_{e}$ was carried out by increasing it by up to two orders of magnitude with respect to the reference value. $R>0$ is a numerical parameter and it was increased and decreased with respect to $R=1$ considering $R=0.25,0.5,1.5$. Values of $\lambda$ were chosen to be physically representative of the Alsina et al. (2016) configuration. Therefore, $\lambda=H_{r m s}=0.39 \mathrm{~m}$ and $\lambda=d=2.48 \mathrm{~m}$ at WG3 were selected.

Figure 6 shows the sensitivity analysis for the parameters considered in terms of $\Delta z_{b_{f}}$ (Fig. 6a, b and c) and $C$ (Fig. 6d, e and f), respectively. The corresponding nRMSE, $\rho_{m r}$ and RMSTE are presented in Table 4. Note that the experimental $C$ was computed as the average of the observed $C_{z}$ at OBS4 and OBS7, which were located at two different $d_{z}$ above the initial $z_{b}$ at AWG7 (OBS4 at $d_{z}=0.03 \mathrm{~m}$ and OBS7 at $d_{z}=0.08 \mathrm{~m}$ ). The OBSs did not measure when the free surface was lower than the instrument sensor. Therefore, the corresponding nRMSE and $\rho_{m r}$ were computed when at least one of the two OBSs was submerged.

The sensitivity analysis reveals that $m_{e}$ is the most influencing parameter within the ranges considered for both the predicted $C$ and $\Delta z_{b_{f}}$. Variations of $\lambda$ and $R$ affect $C$ more than $\Delta z_{b_{f}}$ in terms of nRMSE. By increasing $\lambda$ or $R, C$ decreases and the nRMSE increases due to the increasing underestimation of $C$. For both $\lambda$ and $R$, the maximum relative difference in terms of nRMSE is $14 \%$. Instead, for $m_{e}$, the difference between the maximum and minimum nRMSE is $73 \%$. The sensitivity analysis shows that the variation of the parameters included in the Pritchard and Hogg (2003) model leads to a variability of its peaks and magnitude, as a consequence of the variability of $C$. However, for all the parameters considered, the low values of $\rho_{m r}$ highlight a poor correlation between the modelled and experimental $C$. For $\Delta z_{b_{f}}$, variations of $\lambda$ and $R$ lead to negligible differences in terms of the corresponding nRMSE; differences in terms of RMSTE are lower than $0.05 \%$ and $0.8 \%$ for $\lambda$ and $R$, respectively. $\Delta z_{b_{f}}$ is quantitatively more sensitive to the variation of $m_{e}$, with the difference between the maximum and minimum RMSTE being $25 \%$. From a qualitative point of view, XBNH-IWST is able to capture the peak of the accretion in the upper swash zone if $m_{e}$ is increased by two orders of 
Fig. 5 Alsina et al. (2016) experimental domain with instrumentation installed and location of upstream boundary location in XBNH-IWST model domain (red-dashed line)

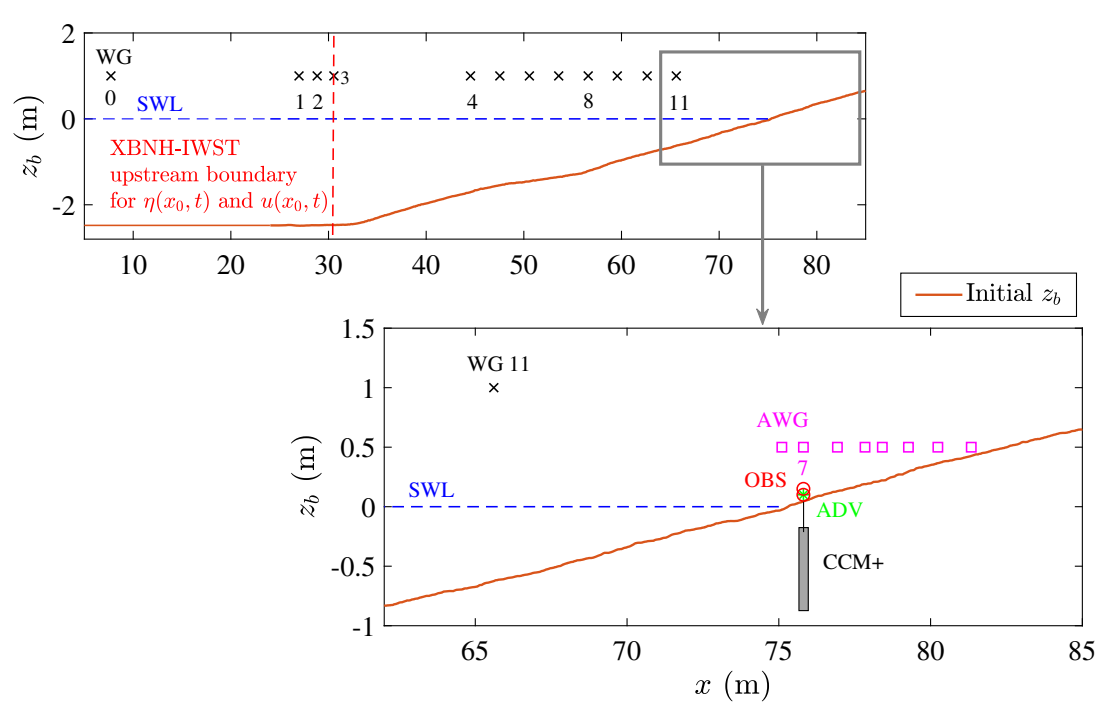

magnitude with respect to the values suggested in Zhu and Dodd (2015). In particular, the predicted erosion pattern in the upper swash region evolves into a deposition one for $m_{e} \geq 0.05 \mathrm{~m} / \mathrm{s}$. Also, by increasing $m_{e}$, the erosion in the lower swash region increases and the peak of deposition in the surf zone moves shoreward.

Different combinations of values for $m_{e}, \lambda$ and $R$ were selected within the ranges considered, for the model calibration. Results are shown in Fig. 7 and the corresponding nRMSE, $\rho_{m r}$ and RMSTE are presented in Table 5. Figure 7 shows that by increasing $m_{e}$ by an order of magnitude with respect to $m_{e}=0.002 \mathrm{~m} / \mathrm{s}$, in combination with different values of $\lambda$ and $R$ than their reference values, the predicted $\Delta z_{b_{f}}$ and $C$ (Fig. 7a and b) are qualitatively comparable with those obtained with $m_{e} \sim 10^{-1} \mathrm{~m} / \mathrm{s}$ and the other parameters set to their reference values. None of the sets of parameters tested allows obtaining a better reproduction of the time history of $C$. The combination $m_{e}=0.01 \mathrm{~m} / \mathrm{s}, \lambda=0.39 \mathrm{~m}$ and $R=1.5$ was chosen for both the Alsina et al. (2016) and Young et al. (2010) test cases because it allows better capturing the magnitude of the deposition in the upper swash zone and the erosion in the lower swash region. This is confirmed by the corresponding lower RMSTE than the other values tested. a

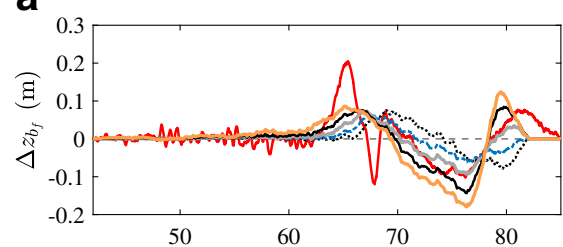

b

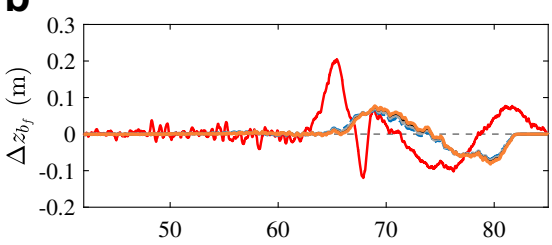

C

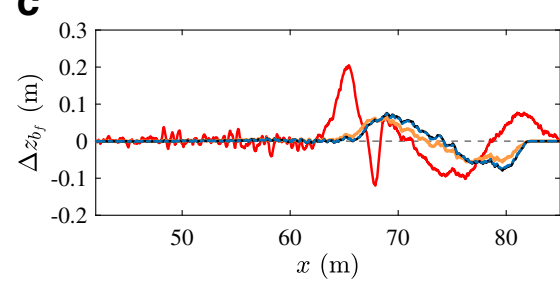

d

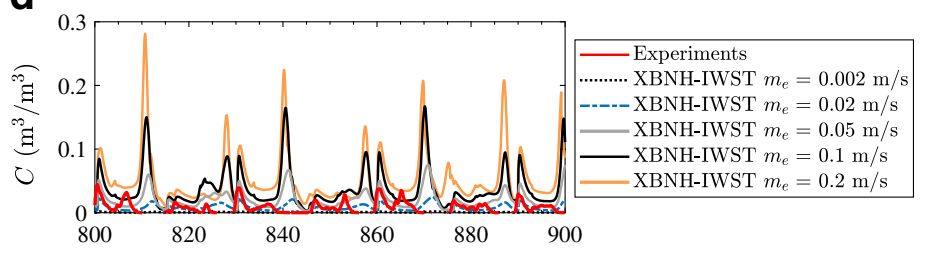

e

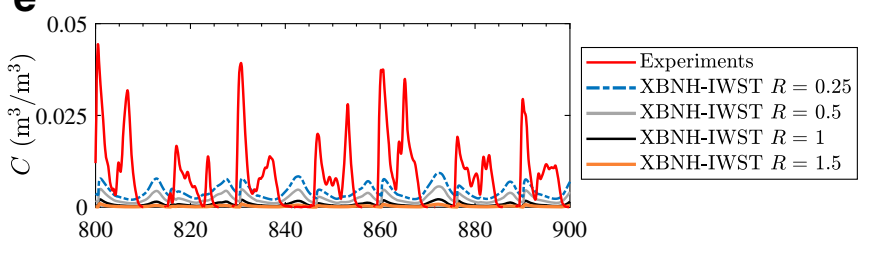

f

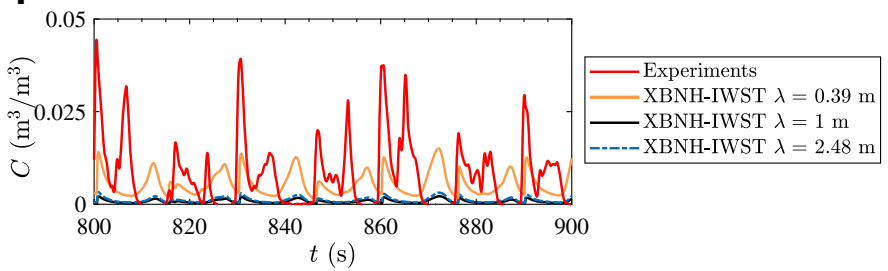

Fig. $6 \Delta z_{b_{f}}$ after SEG1 and time series of $C$ over SEG1 for different values of $m_{e} \mathbf{a}$ and $\mathbf{d}, R \mathbf{b}$ and $\mathbf{e}$, and $\lambda \mathbf{c}$ and $\mathbf{f}$ for BE1_2; for each parameter, the others are set to their reference values (i.e., $m_{e}=0.002$ $\mathrm{m} / \mathrm{s}, R=1$ and $\lambda=1 \mathrm{~m}$ ); reference line: grey dashed line. Note that the scale of the vertical axis in $\mathbf{e}$ and $\mathbf{f}$ is an order of magnitude lower than that in $\mathbf{d}$ 
Table 4 nRMSE and $\rho_{m r}$ for $C$, and nRMSE and RMSTE $\Delta z_{b_{f}}$ for different values of $m_{e}, R$ and $\lambda$; note that for each parameter the others are considered to their default values

\begin{tabular}{|c|c|c|c|c|c|c|c|c|c|c|c|}
\hline & & \multicolumn{5}{|c|}{$m_{e}(\mathrm{~m} / \mathrm{s})$} & \multicolumn{3}{|l|}{$R$} & \multicolumn{2}{|l|}{$\lambda(\mathrm{m})$} \\
\hline & & 0.002 & 0.02 & 0.05 & 0.1 & 0.2 & 0.25 & 0.5 & 1.5 & 0.39 & $2.48 \mathrm{~m}$ \\
\hline \multirow[t]{2}{*}{ C } & nRMSE & 1.1385 & 1.0195 & 1.7786 & 3.2594 & 3.8642 & 1.0046 & 1.0696 & 1.1634 & 0.9757 & 1.1204 \\
\hline & $\rho_{\mathrm{mr}}$ & 0.1319 & -0.0784 & -0.0997 & -0.0688 & -0.0532 & 0.0344 & 0.0721 & 0.2164 & 0.1028 & 0.1486 \\
\hline \multirow[t]{2}{*}{$\Delta z_{b_{f}}$} & nRMSE & 0.0580 & 0.0484 & 0.0403 & 0.0397 & 0.0469 & 0.0550 & 0.0565 & 0.0587 & 0.0519 & 0.0574 \\
\hline & $\operatorname{RMSTE}\left(\mathbf{m}^{2}\right)$ & 0.1792 & 0.1800 & 0.1876 & 0.2022 & 0.2414 & 0.1932 & 0.1834 & 0.1791 & 0.1802 & 0.1799 \\
\hline
\end{tabular}

\subsection{Comparison between model predictions and observations}

The hydrodynamics response of XBNH-IWST is very similar to that presented in Ruffini et al. (2020). For this reason only the nRMSE and $\rho_{m r}$ for $\eta$ at selected crossshore locations are shown in Table 6 .

Figures 8 and $9 \mathbf{a}$ show the variation of $H_{r m s}$ along the beach profile during SEG2 for BE1 2 and BE4_2, respectively. For both wave conditions, the model is able to capture the evolution of $H_{r m s}$ across the domain. $z_{b_{f}}$ and $\Delta z_{b_{f}}=z_{b}\left(t=t_{f}, x\right)-z_{b}(0, x)$ (with $t_{f}$ being the time at the end of SEG2) are illustrated in Figs. 8 and 9 (b and c, respectively); see Table 7 for the corresponding computed nRMSE and RMSTE. Numerical results show a better performance for BE1_2 than BE4_2, in both the surf and swash zones. This is indicated by the lower nRMSE for BE1_2 compared with BE4_2. For the former, XBNH-IWST can capture the deposition in the upper swash zone and the erosion in the lower swash region, whereas the development of the breaker bar is not accurately simulated for both wave conditions. Consequently, $H_{r m s}$ is more underestimated in the shoaling zone for BE4_2 than in BE1_2. Indeed, the experimental results suggest that reflection occurred in the shoaling zone due to the bar; thus, $H_{r m s}$ increased more than the predicted one.

The net sediment transport rate, $\bar{q}_{\text {sed }}$, over SEG1 and SEG2 is shown in Figs. 8 and 9d for BE1_2 and BE4_2, respectively. This was computed using a sediment balance, which was numerically integrated over the $x$-domain between the start of SEG1 and the end of SEG2:

$\bar{q}_{s e d}\left(x=x_{i}\right)=\bar{q}_{s e d}\left(x=x_{i-1}\right)-\left(1-n_{p}\right) \frac{\Delta z_{b_{S E G 1-2}} \Delta x}{\Delta t_{S E G 1-2}}$,

where $q_{\text {sed }}$ is the instantaneous sediment transport and the bar refers to the averaging over the duration of the two segments, $\Delta t_{S E G 1-2}$; the subscript $i$ refers to the $i$ th point along the $x$-domain for both the numerical mesh and the experimental domain, where $z_{b}$ is available. Thus, $i=1, \ldots N$, with $i=1$ at the onshore boundary of the domain (i.e., landward of the maximum run-up limit), where $q_{\text {sed }}=0$ is assumed, and $i=N$ at the offshore start of the beach. $\Delta z_{b_{S E G 1-2}}$ is the difference between $z_{b}$ at the end of SEG2 and at the start of SEG1. Figure 8 (d) highlights that XBNH-IWST is able to simulate the magnitude of the onshore-directed sediment transport in the upper swash zone and the offshore-directed one in the lower swash region and surf zone up to the crest of the bar, located at $x=65 \mathrm{~m}$ (see also Appendix 3). For BE4_2, the model can capture the sign of $\bar{q}_{\text {sed }}$ up to the bar at $x=63$ $\mathrm{m}$ (Fig. 9d), but the magnitude is underestimated. This might be explained by the more prominent bar observed in BE4_2 than BE1_2, which XBNH-IWST cannot reproduce. Therefore, the exchange of sediment between the swash and surf zones is not well simulated, resulting in a deterioration
Fig. $7 \quad \Delta z_{b_{f}}$ a after SEG1 and time series of $C$ b over SEG1 for BE1_2 for different combinations of values of $m_{e}, R$ and $\lambda$; reference line: grey dashed line

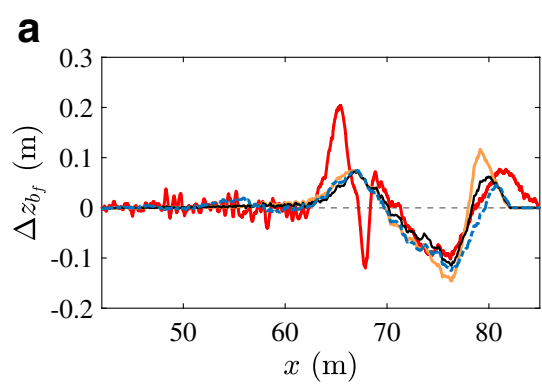

b

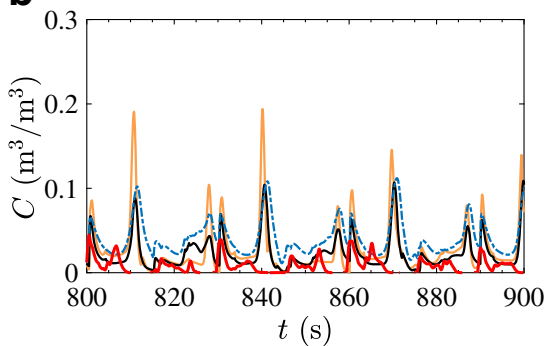

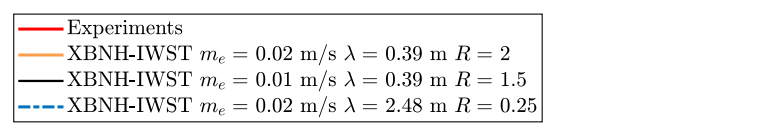


Table 5 nRMSE and $\rho_{m r}$ for $C$, and nRMSE and RMSTE $\Delta z_{b_{f}}$ for different combinations of values of $m_{e}, R$ and $\lambda$

\begin{tabular}{|c|c|c|c|c|}
\hline & $m_{e}(\mathrm{~m} / \mathrm{s})$ & 0.02 & 0.01 & 0.02 \\
\hline & $\lambda(\mathrm{m})$ & 0.39 & 0.39 & 2.48 \\
\hline & $R$ & 2 & 1.5 & 0.25 \\
\hline \multirow[t]{2}{*}{$C$} & nRMSE & 2.8873 & 2.1614 & 3.0819 \\
\hline & $\rho_{\mathrm{mr}}$ & 0.0921 & -0.0913 & -0.1314 \\
\hline \multirow[t]{2}{*}{$\Delta z_{b_{f}}$} & nRMSE & 0.0418 & 0.0412 & 0.0404 \\
\hline & $\operatorname{RMSTE}\left(\mathbf{m}^{2}\right)$ & 0.1896 & 0.1688 & 0.2918 \\
\hline
\end{tabular}

in the overall modelling of $\bar{q}_{\text {sed }}$. For both wave conditions, some limitations are visible in the shoaling region and surf zone up to the bar crest, where the experimental onshoredirected $\bar{q}_{s e d}$ is not predicted by the model. Indeed, when the experimental $\bar{q}_{\text {sed }}$ changes in sign, the modelled one continues being negative for both wave conditions. Note that for BE4 2 the observed $\bar{q}_{\text {sed }}$ goes to zero at the offshore boundary, which is not shown in Fig. 9d. However, the positive and quasi-uniform value of the observed $\bar{q}_{\text {sed }}$ in the shoaling zone is most likely affected by measurement effects due to the mechanical wheel profiler used to measure the bed level. This instrument has a wheel that is too large to detect individual ripples. Therefore, the change in the bed level is below the sensitivity of the instrument. Moreover, the modelled $\theta$ at the offshore side of the bar is larger than $\theta_{c r}$ for the most part of the event.

A detailed analysis of the local sediment transport dynamics within SEG2 at AWG7 $(x=75.81 \mathrm{~m})$ is shown in Figs. 10 and 11 for BE1_2 and BE4_2, respectively. Note that the observed $u$ is a local measurement and herein assumed depth-uniform. The experimental timedependent $z_{b}$ recorded by the CCM+ tank at the same $x$ was used to compute $C_{z}$ for XBNH-IWST with Eq. (15). For BE1_2, only two groups are selected from the sequence of groups within $T_{r}$ over SEG2. Figure 10b and $\mathbf{c}$ show the time series of $C_{z}$ for both the model and observations at OBS4 and OBS7, respectively. Results show that the initial peak of the intra-wave $C_{z}$ corresponding to the first bore of both groups (at $t / T_{r} \simeq 0.005$ and $t / T_{r} \simeq$ 0.084 , respectively) is captured by XBNH-IWST, as well

Table 6 nRMSE and $\rho_{m r}$ for $\eta$ at three locations: WG4 $(x=44.54$ $\mathrm{m})$, WG8 $(x=56.59)$ and AWG7 $(x=75.81 \mathrm{~m})$, for wave conditions BE1_2 and BE4_2

\begin{tabular}{|c|c|c|c|c|}
\hline & \multicolumn{2}{|c|}{ nRMSE } & \multicolumn{2}{|l|}{$\rho_{\mathrm{mr}}$} \\
\hline & BE1_2 & BE4_2 & BE1_2 & BE4_2 \\
\hline WG4 & 0.3427 & 0.2935 & 0.9434 & 0.9047 \\
\hline WG8 & 0.3703 & 0.3480 & 0.9319 & 0.7091 \\
\hline AWG7 & 0.6343 & 0.4928 & 0.8492 & 0.7387 \\
\hline
\end{tabular}

as the order of magnitude of $C_{z}$ corresponding to the peaks of $u$. However, the correlation between the predicted and observed $C_{z}$ is affected by the underestimation of $C_{z}$ close to flow reversal, as confirmed by the corresponding nRMSE and $\rho_{m r}$, shown in Table 7 , which reflect a lower performance of XBNH-IWST compared with the hydrodynamics modelling. Figure 10d shows the modelled $q_{s}$ and $q_{b} ; q_{s}$ being always higher than $q_{b}$. In the broadbanded wave condition, large backwashes are allowed to develop. Consequently, the suspension of sediment particles is dominant with respect to the sediments settling.

BE4_2 allows analysis of results within one group over SEG2, since $T_{r}=T_{g}$. Note that the observed $u$ was filtered with a low-pass filter (cut-off frequency set to $3 \mathrm{~Hz}$ ) to remove the noise in the measurements. Similarly to BE1_2, XBNH-IWST is able to capture the order of magnitude of the observed $C_{z}$ after the first event due to swash-swash interactions present in the group at OBS4, whereas, except for the first uprush within the group, $C_{z}$ is underestimated at OBS7 (Fig. 11b and c, respectively). The peak in the modelled $C_{z}$ corresponding to the first wave (at $t / T_{r} \simeq 0.095$ ) might be the result of a larger bore-induced advection than observations. The lower model performance for BE4_4 than BE1 2 is reflected by the higher nRMSE for $C_{z}$, while the values of $\rho_{m r}$ are of the same order of magnitude of those for the broad-banded wave condition (see Table 7). In BE4_2, a higher number of swash-swash interactions occurred within the group than in BE1_2. Therefore, backwashes corresponding to subsequent events were allowed to develop for a shorter duration compared with the broad-banded wave condition. Consequently, the observed and predicted $C_{z}$ are lower and the difference between the modelled $q_{s}$ and $q_{b}$ (Fig. 11d) is smaller than in BE1_2. Indeed, $q_{b}>q_{s}$ during the backwash events within the group.

\section{Numerical modelling of consecutive non-interacting solitary waves over a sloped beach}

In this section, the performance of XBNH-IWST is further tested against the experiments of an erodible sloped beach exposed to nine consecutive non-interacting solitary waves presented in Young et al. (2010). Similarly to Zhu and Dodd (2015), this case allows an individual swash event and the evolution of the beach to be examined without the presence of swash-swash interactions occurring in wave groups.

Figure 12 shows the experimental set-up and the location of the instrumentation installed in Young et al. (2010) and considered for comparison in this study. For $\eta$, WG8 $(x=$ $23 \mathrm{~m})$ and the Distance Sonic, DS2 $(x=29 \mathrm{~m})$ sensors were considered. For $u$, ADV8 $(x=23 \mathrm{~m})$ and $\operatorname{ADV} 5(x=$ 
Fig. 8 Cross-shore profile of

$H_{r m s}$ a over SEG2; $z_{b_{f}} \mathbf{b}$ and

$\Delta z_{b_{f}} \mathbf{c}$ after SEG2; $\bar{q}_{\text {sed }}$ over

SEG1 and SEG2 d for BE1_2;

reference line: grey dashed line

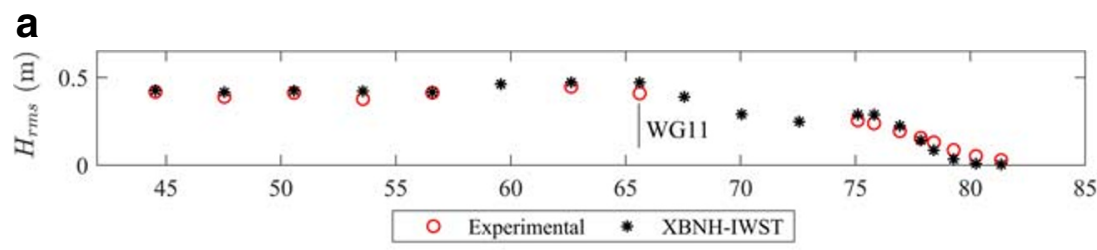

b

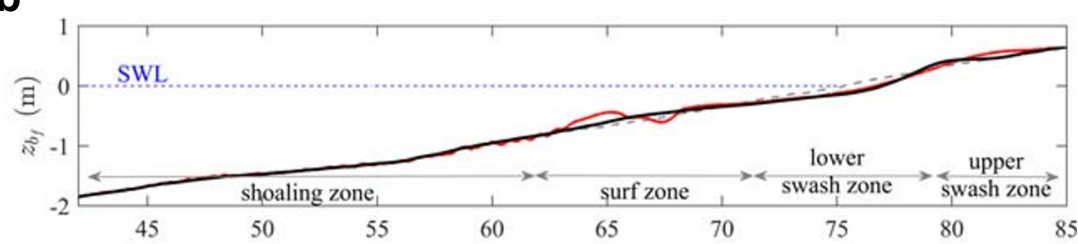

C

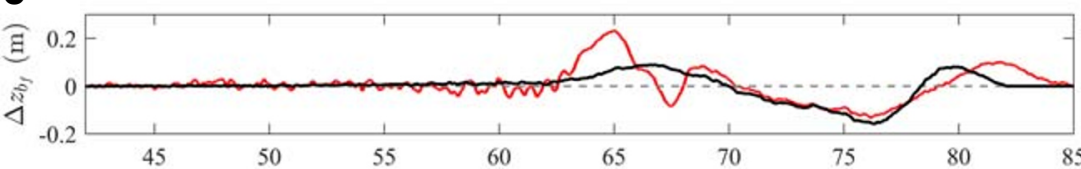

d

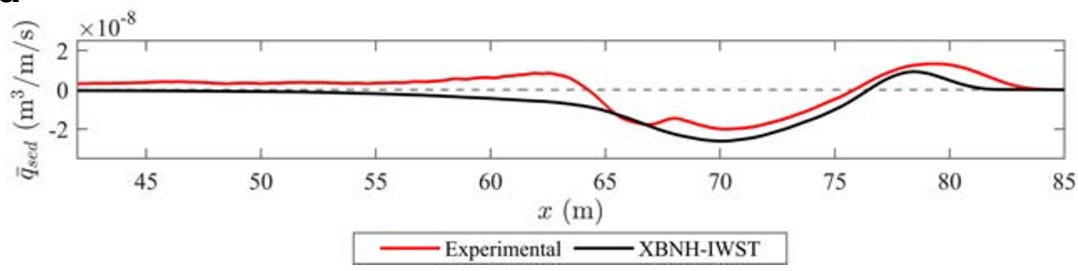

$29 \mathrm{~m}$ ), sensors were selected. For the suspended sediment concentration, OBS3 and OBS4 sensors were considered $(x=23 \mathrm{~m})$. The OBS3 and OBS4 sensors recorded $C_{z}$ at two different $d_{z}$ from the initial $z_{b}$ (OBS3 at $d_{z}=0.19 \mathrm{~m}$ and OBS4 at $d_{z}=0.09 \mathrm{~m}$ ). The initial $z_{b}$ is a wave-modified 1:15 sloped beach, made of well-sorted sand with $D_{50}=$
Fig. 9 Cross-shore profile of $H_{r m s}$ a over SEG2; $z_{b_{f}}$ b and $\Delta z_{b_{f}} \mathbf{c}$ after SEG2; $\bar{q}_{\text {sed }}$ over SEG1 and SEG2 d for BE4_2; reference line: grey dashed line

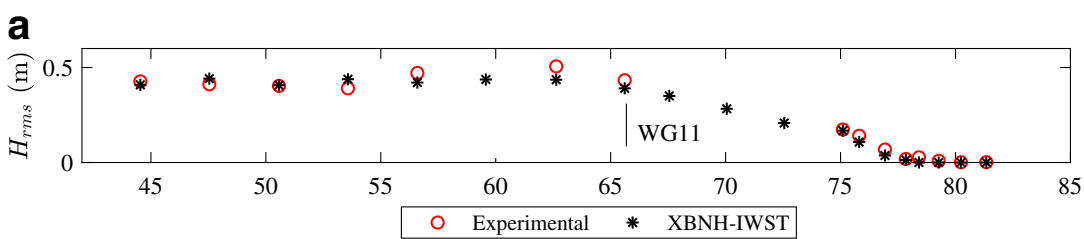

b

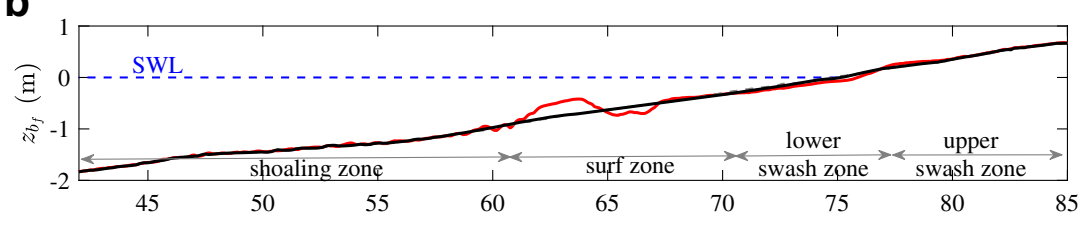

C

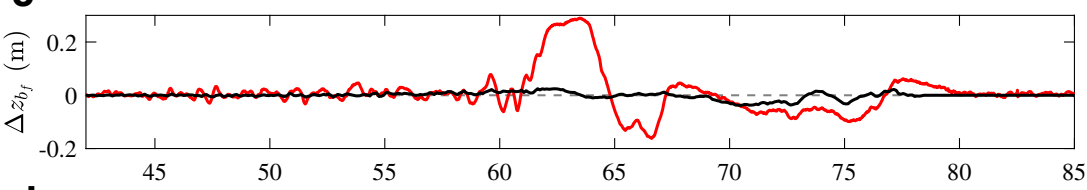

d

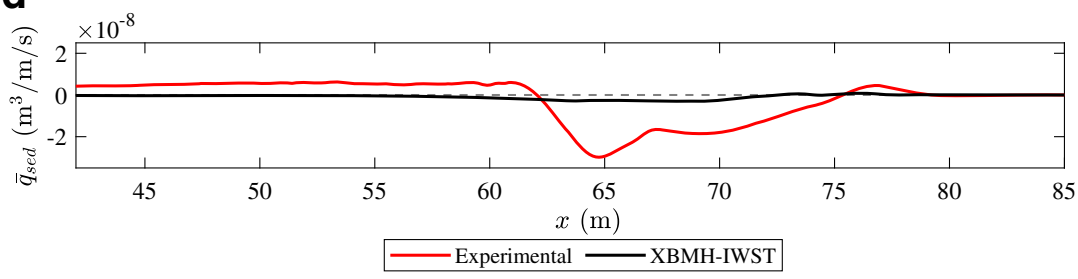


a

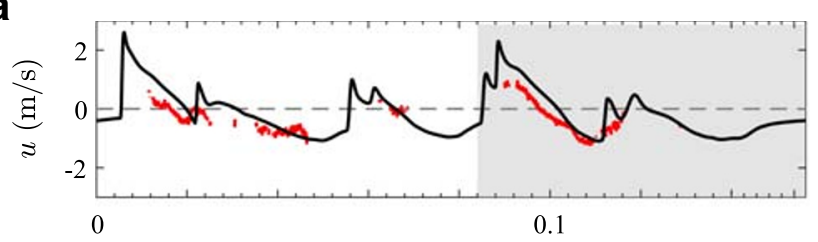

b
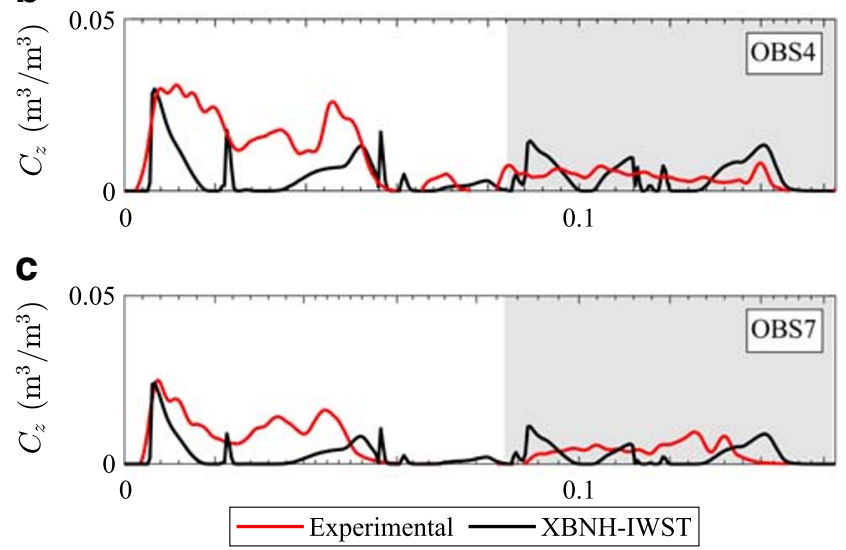

d

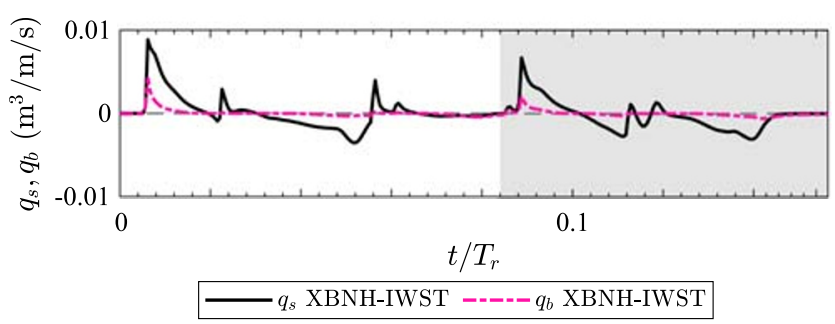

Fig. 10 Time series of flow and sediment transport variables at AWG7 over SEG2 for BE1 $\_: u \mathbf{a} ; C_{z}$ at OBS4 $\mathbf{b} ; C_{z}$ at OBS7 $\mathbf{c} ; q_{s}$ and $q_{b}$ d; the shaded area distinguishes the two wave groups; reference line: grey dashed line

$0.2 \mathrm{~mm}$ and $n_{p}=0.4$. This configuration was the result of previous runs on the nominal 1:15 sloped $z_{b}$, such that it can be considered as a near-equilibrium profile beach state.

\subsection{Model set-up and parameters}

The model domain was set up following the experimental settings, described in detail in Young et al. (2010). The computational domain was $x_{0}=0 \leq x \leq 40 \mathrm{~m}$ and $\Delta x=$ $0.05 \mathrm{~m}$. The initial wave-modified $z_{b}$ was used as the initial $z_{b}$ in the simulations. As shown in Fig. 12, time series of $\eta$ and $u$ were updated at the upstream boundary located at $x_{0}$, and were given by Titov and Synolakis (1995), considering a solitary wave over the initial $d=1 \mathrm{~m}$ :

$\eta\left(x_{0}, t\right)=H \operatorname{sech}^{2}\left[\sqrt{\frac{3 H}{4 d^{3}}}\left(c t-x_{0}\right)\right]$,

where $H=0.60 \mathrm{~m}$ and $u$ is:

$u\left(x_{0}, t\right)=\eta\left(x_{0}, t\right) \sqrt{\frac{g}{h}}$. a

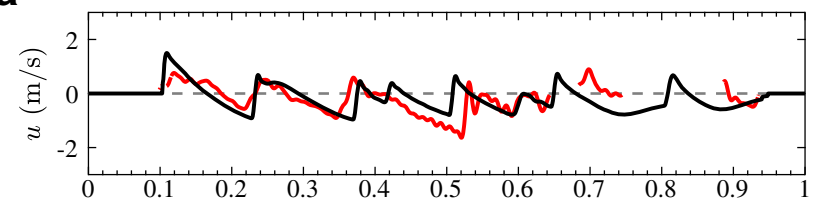

b
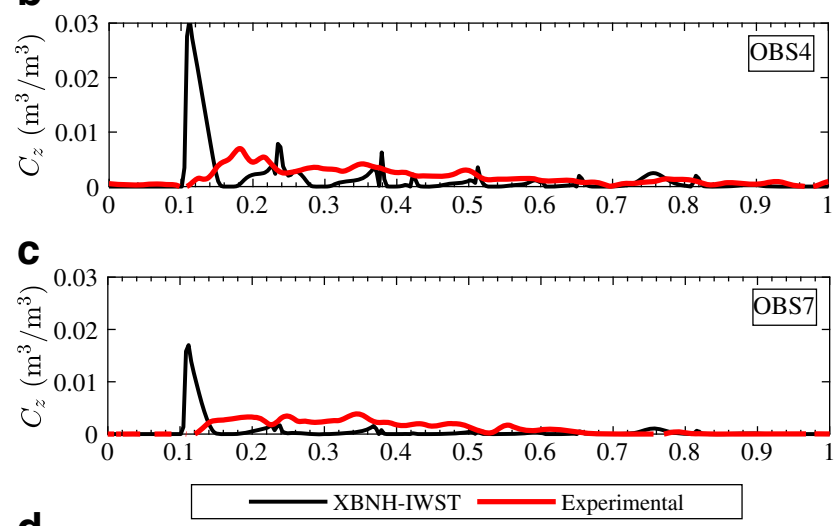

d

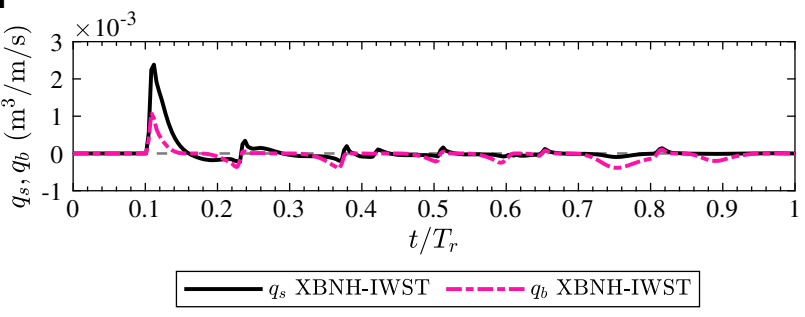

Fig. 11 Time series of flow and sediment transport variables at AWG7 over SEG2 for BE4_2: $u \mathbf{a} ; C_{z}$ at OBS4 $\mathbf{b} ; C_{z}$ at OBS7 $\mathbf{c} ; q_{s}$ and $q_{b} \mathbf{d}$; reference line: grey dashed line

Moreover, to be consistent with the observations, a reflection was taken into account at the upstream boundary. The sediment transport model was set up similarly to the Alsina et al. (2016) test case (see Table 3), with $\lambda=H$. $c_{f}$ was modelled using $n=0.025 \mathrm{~s} / \mathrm{m}^{1 / 3}$, which was chosen matching the simulated maximum run up with the observations. The maximum excursion point was observed at $x=38.5 \mathrm{~m}$. Parameters that were not mentioned in this study were set to their default values defined in Deltares (2015). Numerical simulations were performed for the first three waves of the nine experimental runs. Following the

Table 7 Values of nRMSE, RMSTE and $\rho_{m r}$ for $\Delta z_{b_{f}}$ and $H_{r m s}$ along $x, u$ and $C_{z}$ at $x=75.81 \mathrm{~m}$ for wave conditions BE1_2 and BE4_2

\begin{tabular}{|c|c|c|c|c|c|c|}
\hline & BE1_2 & BE4_2 & BE1_2 & BE4_2 & BE1_2 & BE4_2 \\
\hline & \multicolumn{2}{|l|}{ nRMSE } & \multicolumn{2}{|l|}{$\rho_{\mathrm{mr}}$} & \multicolumn{2}{|c|}{$\operatorname{RMSTE}\left(\mathbf{m}^{2}\right)$} \\
\hline$\Delta z_{b_{f}}$ & 0.0464 & 0.0712 & & & 0.4078 & 0.3217 \\
\hline$H_{r m s}$ & 0.2402 & 0.3005 & & & & \\
\hline$u$ & 0.5706 & 0.8526 & 0.6443 & 0.5103 & & \\
\hline$C_{z}(\mathrm{OBS} 4)$ & 1.0665 & 3.0683 & 0.3319 & 0.3033 & & \\
\hline$C_{z}$ (OBS7) & 1.0805 & 2.4130 & 0.2521 & 0.2148 & & \\
\hline
\end{tabular}




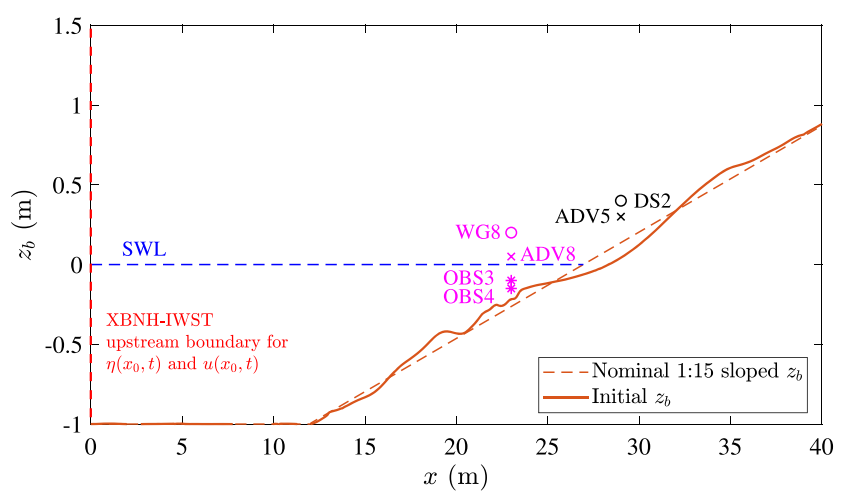

Fig. 12 Young et al. (2010) experimental set-up with instruments installed and location of the upstream boundary in XBNH-IWST model domain (red dashed line)

experimental procedures, the simulated time for each wave was $900 \mathrm{~s}$, in order to allow the water to calm.

\subsection{Comparison between model predictions and observations}

Figure 13 shows the numerical and experimental time series of $\eta$ and $u$ within one wave at selected $x$. In general, XBNHIWST is able to capture the hydrodynamics. However, a shift of $4 \mathrm{~s}$ in the prediction of the reflected wave due to the finite size of the flume is also visible, which affects the corresponding nRMSE and $\rho_{m r}$ (see Table 8). At WG8 (Fig. 13a), the average overestimation of $\eta$ after the wave run-down, including the reflected wave (i.e., for $t>22 \mathrm{~s}$ ), is equal to $8 \%$. Comparison at ADV5 (Fig. 13d) is affected by some noise in the collected signal at $t=10 \mathrm{~s}$ and when the water level dropped down the sensor $(17<t<37 \mathrm{~s})$; hence, no signal was recorded.

Figure 14 shows $z_{b_{f}}$ (a) and $\Delta z_{b_{f}}$ (b) after 3 waves $\left(z_{b_{f}}=z_{b}\left(x, t_{f}\right)\right.$, with $t_{f}=$ time at the end of the third run. Despite the overestimation of the deposition in the upper swash zone and the erosion in the lower swash region for $x>30.5 \mathrm{~m}, \mathrm{XBNH}-\mathrm{IWST}$ is able to reproduce the observed
Table 8 Values of nRMSE and $\rho_{m}$ for $\eta, u$ and $C$ at selected positions and $\Delta z_{b_{f}}$ along $x$, and RMSTE for $\Delta z_{b_{f}}$

\begin{tabular}{llllll}
\hline & & & nRMSE & $\boldsymbol{\rho}_{\mathbf{m r}}$ & RMSTE $\left(\mathbf{m}^{2}\right)$ \\
\hline 1 wave & WG8 & $\eta$ & 1.1839 & 0.5612 & \\
& ADV8 & $u$ & 0.7095 & 0.7465 & \\
& DS2 & $\eta$ & 0.9819 & 0.7642 & \\
& ADV5 & $u$ & 1.4419 & 0.4609 & \\
\multirow{6}{*}{ 3 waves } & OBS3-4 & $C$ & 5.7473 & 0.5296 & \multirow{2}{*}{0.0866} \\
\hline
\end{tabular}

erosion and deposition patterns. From a quantitative point of view, this is confirmed by the corresponding nRMSE and RMSTE, which are shown in Table 8.

An analysis of the intra-wave sediment transport within one wave is shown in Fig. 15 for $x=23 \mathrm{~m}$. Time series of $C$ are shown in Fig. 15b. Note that the experimental $C$ was computed as the average of the observed $C_{z}$ at OBS3 and OBS4. The corresponding computed nRMSE and $\rho_{m r}$ are shown in Table 8. Numerical results show that the largest peak of $C$ corresponds to the backwash phase of the flow (Fig. 15a) (at $t \simeq 20 \mathrm{~s}$ ). According to Young et al. (2010), the large peak of $C$ observed between $t=20 \mathrm{~s}$ and $t=25 \mathrm{~s}$ was possibly due to the dispersion of sediment generated by the hydraulic jump observed during the experiments at $x=24 \mathrm{~m}$.

Time series of the modelled $q_{s}$ and $q_{b}$ are shown in Fig. 15c. At the early stage of the uprush $q_{b} \simeq q_{s}$. This is consistent with the observations, where the experimental $C$ is almost zero in the uprush, which means that sediment motion mainly occurred as near-bed sediment transport. The reason might be addressed by the location of the OBS sensors, which was seaward of the wave plunging point. As the stirred up sediments are entrained in the water column, the contribution of the modelled $q_{s}$ also increases. Close to flow reversal, sediment settling occurs and both predicted $q_{s}$ and $q_{b}$ decrease. During the backwash, $q_{b}$ and $q_{s}$ increase until $q_{s}>q_{b}$ in the stage of the run-down.
Fig. 13 Time series of $\eta$ and $u$ at two representative locations: WG8 and ADV8, $x=23 \mathrm{~m}$ a and $\mathbf{c}$; DS2 and ADV5, $x=29 \mathrm{~m}$ $\mathbf{b}$ and $\mathbf{d}$; reference line: greydashed line. The two subplots in $\mathbf{a}$ and $\mathbf{b}$ show the cross-shore location of the sensors in the model domain, respectively a

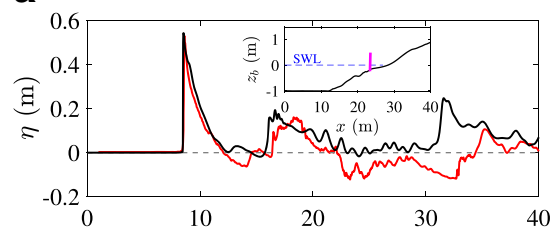

C

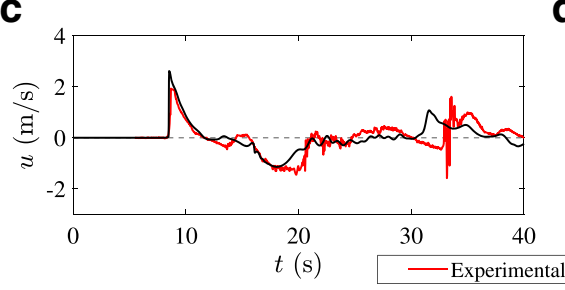

b

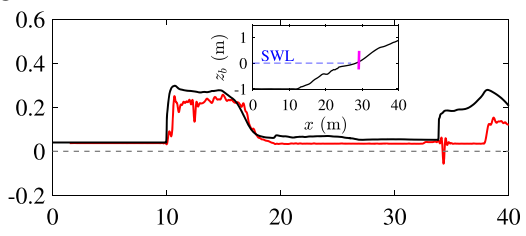

d

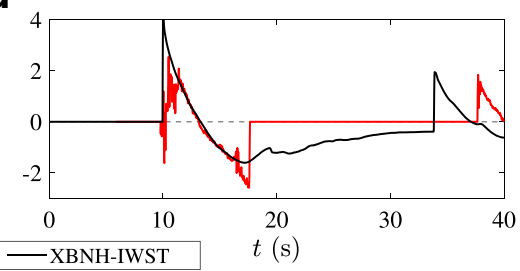




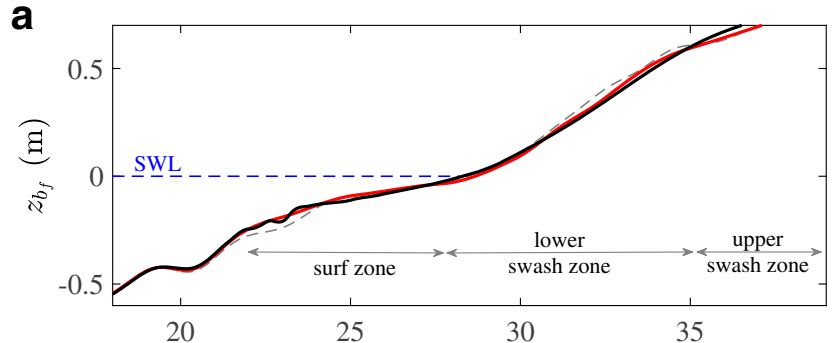

b

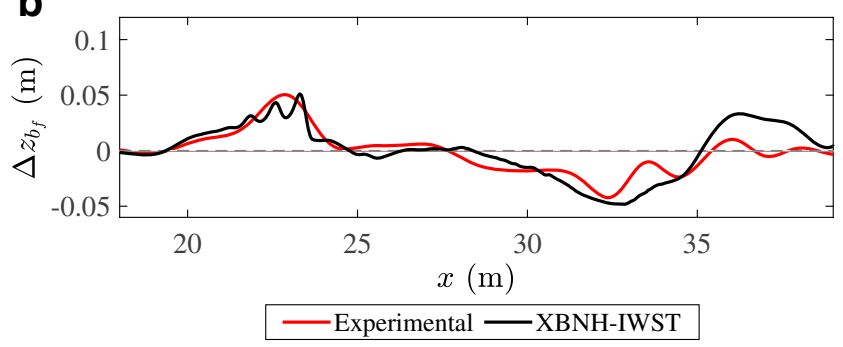

Fig. $14 z_{b_{f}}$ a and $\Delta z_{b_{f}} \mathbf{b}$ after 3 waves; reference line: grey-dashed line

\section{Discussion}

First, the XBNH-IWST modelling of sediment transport and morphodynamics is discussed by comparing the results of numerical simulations of the Alsina et al. (2016) case obtained in the present study with those of Ruffini et al. (2020) using the XBNH-WAST approach. Figure 16 shows the XBNH-IWST and XBNH-WAST predictions for SEG2, with a focus on the swash zone for BE1_2 and BE4_2, respectively. Comparison between the modelled and experimental $C$ is shown in Fig. 16d and $\mathbf{h}$ and the corresponding nRMSE, $\rho_{m r}$ and RMSTE are presented in Table 9. The accuracy of XBNH-IWST in the prediction of $C$ in terms of nRMSE and $\rho_{m r}$ is similar to that of XBNHWAST (see Table 9). XBNH-ISWT, however, is able to better describe the sediment suspension observed after the first bore generated by swash-swash interactions within the group and $C$ close to flow reversal. Also, the accuracy of XBNH-IWST in terms of nRMSE and $\rho_{m r}$ is higher when the comparison is carried out for $C_{z}$ (see also Table 7).

Differences in the predictions of $C$ for the two approaches lead, in turn, to differences in the simulated $\Delta z_{b_{f}}$ (Fig. 16a and e). XBNH-IWST shows a better performance in the prediction of $\Delta z_{b_{f}}$ than XBNH-WAST; for BE1_2, the RMSTE of the former approach is lower by $21 \%$ than that of the latter one, while for BE4 2 the difference is $10 \%$. XBNH-IWST better simulates the deposition in the upper swash zone and the erosion in the lower swash region. In fact, $\Delta z_{b_{f}}$ predicted with XBNH-WAST diverges from observations, especially in the upper swash zone. This might be explained by the behaviour of the sediment transport model in XBNH-IWST near flow reversal a

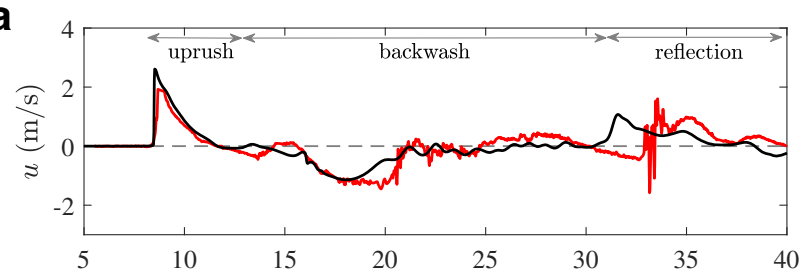

b
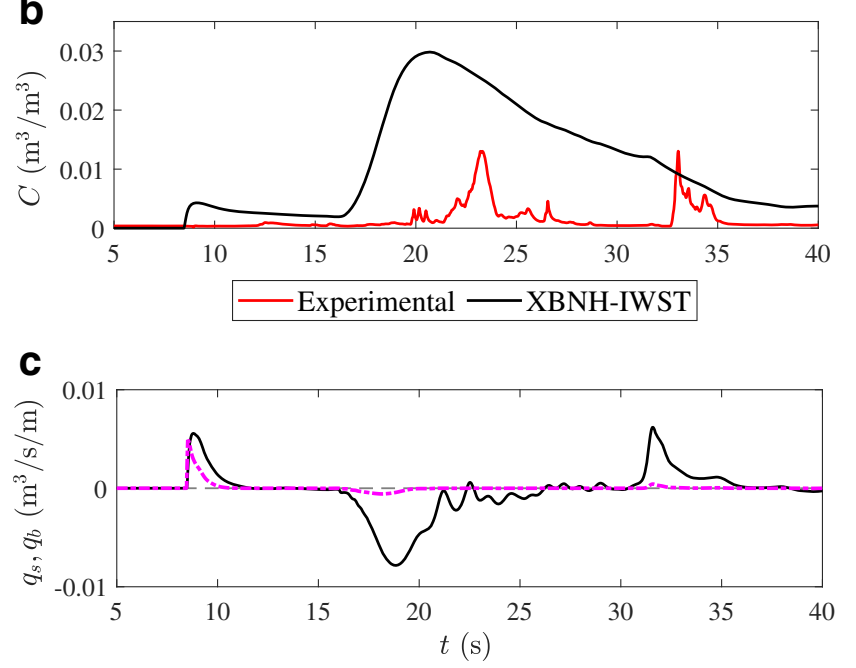

$-q_{s}$ XBNH-IWST ---- $q_{b}$ XBNH-IWST

Fig. 15 Time series of $u \mathbf{a}, C \mathbf{b}, q_{s}$ and $q_{b} \mathbf{c}$ at $x=23 \mathrm{~m}$; reference line: grey dashed line

(i.e., $u=0 \mathrm{~m} / \mathrm{s}$ ), when sediment particles are allowed to settle. The better performance of the present approach is confirmed by the modelling of $\bar{q}_{\text {sed }}$ (Fig. $16 \mathbf{b}$ and f). Unlike the model proposed in this study, XBNH-WAST does not capture the sign of $\bar{q}_{\text {sed }}$ in the upper swash zone.

For the Young et al. (2010) experiments, the predicted $\Delta z_{b_{f}}$ shows lower nRMSE and RMSTE than for the Alsina et al. (2016) case (see Table 8 ) by $60 \%$, and by an order of magnitude respectively. Regarding the intrawave sediment transport, the experimental $C$ was obtained by averaging the measurements performed by OBS3 and OBS4 in the surf zone, where, as indicated in Young et al. (2010), $C_{z}$ was observed to vary a lot along the depth. Therefore, discrepancies between observations and numerical predictions are due to some limitations of the model performance, but uncertainty in the comparison exists because of the low resolution of the measurements.

For both the simulated laboratory experiments, the performance of the Meyer-Peter and Müller (1948) formulation is consistent with results of previous studies (e.g., Xiao et al. 2010 and Postacchini et al. 2012). The modelled $\theta$ for Young et al. (2010) at $x=23 \mathrm{~m}$ is higher than $\theta_{c r}$ for almost the whole duration of both the uprush and backwash events (with maximum values of approximately 15 and 4, respectively). 
Fig. 16 Comparison between XBNH-IWST and

XBNH-WAST (Ruffini et al.

2020) results. $\Delta z_{b_{f}} \mathbf{a}, \mathbf{e} ; \bar{q}_{\text {sed }} \mathbf{b}$, $\mathbf{f}$; time series of $u \mathbf{c}, \mathbf{g}$ and $C$

$\mathbf{d}, \mathbf{h}$ at $x=75.81 \mathrm{~m}$ for BE1_2 and BE4_2, respectively; reference line: grey dashed line; the shaded area distinguishes the two wave groups; the subplot in e indicates the location of the results shown in the main plots along the domain
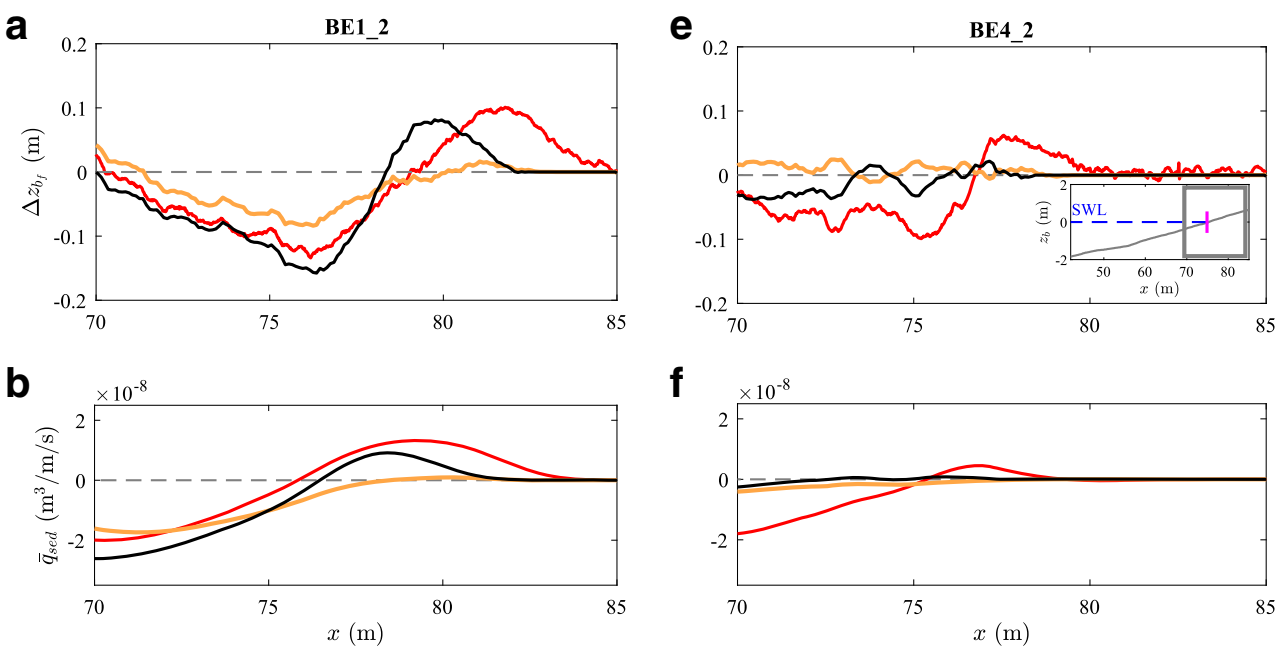

f

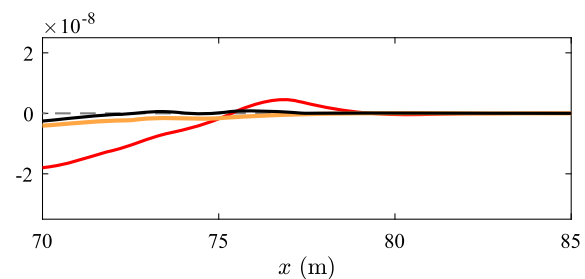

C
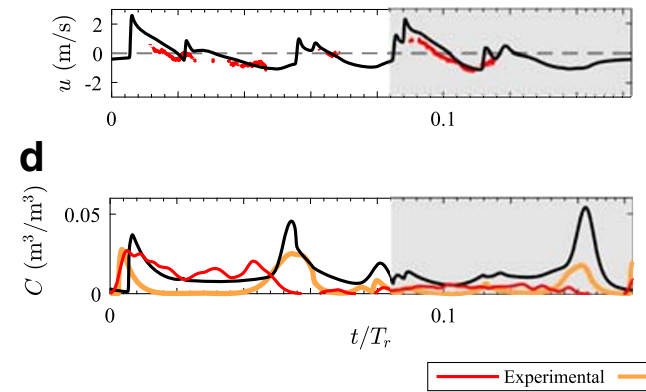

g

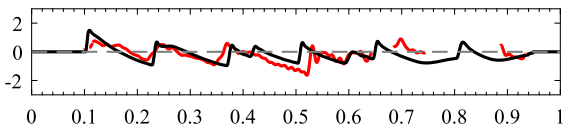

h

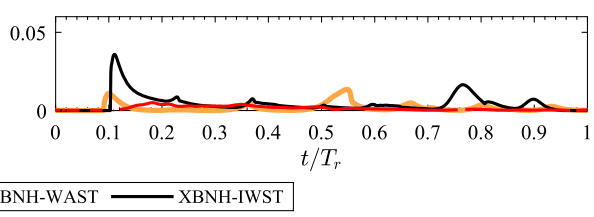

A note of caution should be provided regarding the parameters of the Pritchard and Hogg (2003) transport equation. The sensitivity analysis presented in Section 4.2 showed that $m_{e}$ is the parameter that mostly influences the prediction of $\Delta z_{b_{f}}$ and $C$ (see Table 4 and Fig. 6). However, because no field data are available to provide its estimates, the only comparisons with the findings of the present study are previous numerical studies, such that of Zhu and Dodd (2015). The value of $m_{e}$ that showed best modelling in this study is an order of magnitude larger than that used by the cited study for a single solitary wave when a well-mixed condition is assumed (i.e., $K_{C}=1$ ). The optimal $m_{e}$ found was used in combination with $R=1.5$ ( $R$ being an arbitrary numerical parameter), $\lambda$ equal to the considered wave height at the upstream boundary, and by considering $K_{C} \geq 1$. To simplify the choice of the values corresponding to the parameters considered in the Pritchard and Hogg (2003) expression, $\tau_{b, c r}$ was set equal to 0 . This choice was justified following Zhu and Dodd (2015) who pointed out that the effect of a threshold for suspended load is not significant for sandy beach morphodynamics. $\lambda$ is an arbitrary length scale, which in turn, affects the other scale parameter, $\tau_{\text {ref }}$. Therefore, representative values of $\lambda$ were selected for the model calibration (see Section 4.2). $\tau_{\text {ref }}$ was computed similarly to Zhu and Dodd (2015) for all the simulations carried out.
Although the proposed parameter set allows obtaining a lower RMSTE and a better prediction of erosion and deposition patterns than the other combinations tested, the prediction of $C$ is still inaccurate in XBNH-ISWT as well as the process of bar formation, indicating the need of explicitly modelling further important physical processes. The missing explicit representations of processes such as wave breaking-induced turbulence in the HFA model, phasing effects of the velocity in the BBL, such as the earlier flow reversal near the bottom with respect to the rest of the water column in the swash zone (see e.g., Zhang and Liu 2008), are certainly factors that concur to this inaccuracy.

Table 9 RMSTE for $\Delta z_{b_{f}}$ along the swash zone, and nRMSE and $\rho_{m r}$ for $C$ at $x=75.81 \mathrm{~m}$ for BE1_2 and BE4_2, respectively; comparison between XBNH-IWST and XBNH-WAST (Ruffini et al. 2020 results)

\begin{tabular}{|c|c|c|c|c|}
\hline & \multicolumn{2}{|l|}{ BE1_2 } & \multicolumn{2}{|l|}{ BE4_2 } \\
\hline & XBNH-IWST & XBNH-WAST & XBNH-IWST & XBNH-WAST \\
\hline & nRMSE & & & \\
\hline \multirow[t]{4}{*}{$C$} & 1.3333 & 1.2906 & 5.9385 & 2.3647 \\
\hline & $\rho_{m r}$ & & & \\
\hline & 0.0785 & -0.1005 & 0.2696 & -0.1405 \\
\hline & $\operatorname{RMSTE}\left(\mathbf{m}^{2}\right)$ & & & \\
\hline$\Delta z_{b_{f}}$ & 0.1669 & 0.2089 & 0.0675 & 0.0755 \\
\hline
\end{tabular}




\section{Conclusions}

In this study, the implementation of the Pritchard and Hogg (2003) intra-wave sediment transport equation in XBNH was presented, together with the verification of the model against a high-resolution numerical solution. A sensitivity analysis allowed choosing the set of parameters included in the Pritchard and Hogg (2003) equation that provided the best modelling and the performance of the resulting model was assessed with two laboratory test cases.

Verification of XBH-IWST against Zhu and Dodd (2015) highlighted that the Pritchard and Hogg (2003) transport equation performs qualitatively and quantitatively well when compared with a high-resolution numerical solution of NLSWE. Therefore, this modelling approach is suitable for solving the intra-swash sediment transport in the context of wave-resolving models.

Numerical simulations of the Alsina et al. (2016) and Young et al. (2010) laboratory experiments showed that XBNH-IWST is able to simulate the beach evolution driven by isolated waves, whereas the exchange of sediments between the swash and surf zones under wave trains is not accurately predicted yet. The sediment transport modelling approach herein used is able to improve the simulation of the intra-swash sediment transport within XBNH, especially in terms of $C$ at flow reversal, and in turn, the prediction of the beach accretion in the upper swash zone for the Alsina et al. (2016) case. However, it is not sufficient to accurately capture the mutual feedback between the swash and surf zones when swash-swash interactions are present.

In evaluating the comparisons with the laboratory data, consideration was given to the associated uncertainty. In the Alsina et al. (2016) experiments, a state of the art measurement system was used with high resolution in space and time for the suspended sediment transport. The OBS sensors inevitably provide low-resolution data in the water column. On the other hand, the previous Young et al. (2010) experiments were conducted with fewer instruments. This provides limited resolution for the data. High-resolution experiments of solitary waves on mobile bed are particularly valuable because the intra-wave dynamics could be investigated in depth. Therefore, such experiments are highly recommended for future studies.

At present, there are still limitations in the qualitative and quantitative representation of the morphodynamics and sediment transport with XBNH-IWST. The inclusion of the wave-resolving Pritchard and Hogg (2003) sediment transport equation in $\mathrm{XBNH}$ represents a first step to improve the morphodynamics prediction of the model in the context of sandy beaches evolution. Future work is necessary for an accurate prediction of the mutual feedback between the surf and swash zones. Further work will be addressed to the improvement of the intra-wave sediment transport modelling within XBNH-IWST. Additional physical processes, such as BBL effects and turbulence, and the inclusion of the vertical structure of sediment concentration and flow, need to be included in a formulation suitable for the class of models at hand. A simplified wave breakinginduced turbulence model, similar to those used by Alsina et al. (2009) and Reniers et al. (2013), could be considered to take into account the turbulence diffusion in the computation of $C(z)$ and, in turn, in the prediction of $C$ with XBNH-IWST.

\section{Notation}

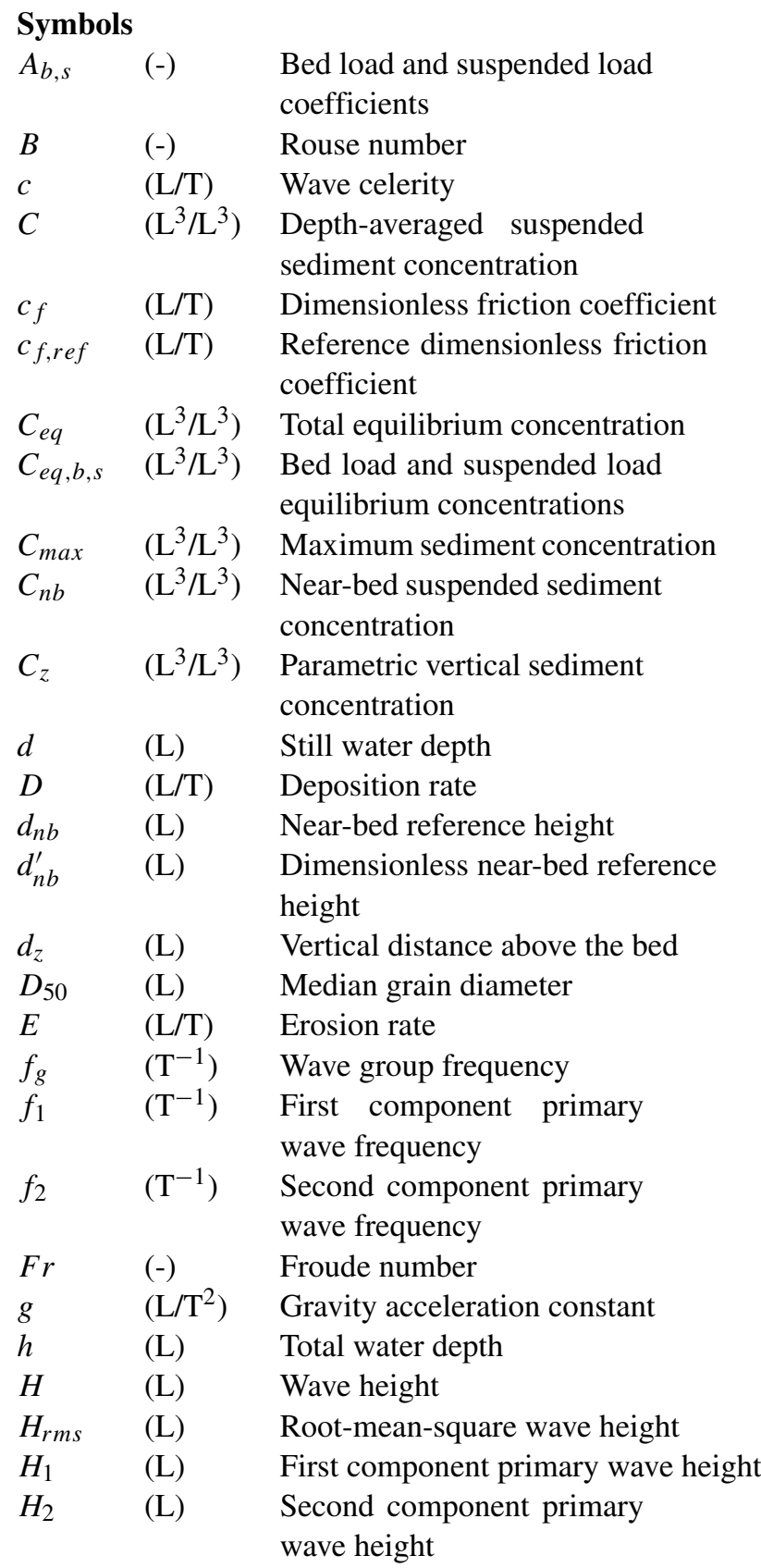




\begin{tabular}{|c|c|c|c|c|c|}
\hline$K_{C}$ & $(-)$ & Shape factor & $\Delta t$ & $(\mathrm{~T})$ & Computational time interval \\
\hline$k_{w}$ & $(-)$ & Wave number & $\Delta t_{S E G 2}$ & $(\mathrm{~T})$ & Duration of SEG2 \\
\hline$L$ & (L) & Wave length & $\Delta x$ & (L) & Computational $x$-grid size \\
\hline$m_{e}$ & $(-)$ & Mobility parameter & $\Delta z_{b}$ & (L) & Bed changes \\
\hline$n$ & $(-)$ & Manning coefficient & $\Delta z_{b_{f}}$ & $(\mathrm{~L})$ & Final bed changes \\
\hline$n_{p}$ & $(-)$ & Bed porosity & $\Delta z_{b_{S E G 2}}$ & (L) & Difference between final and \\
\hline$n_{p, d}$ & $(-)$ & Bed porosity for a fluidised bed & & & initial bed level of SEG2 \\
\hline$N$ & $(-)$ & Number of samples & $\eta$ & (L) & Water surface elevation \\
\hline$p_{n h}$ & $\left(\mathrm{~L} / \mathrm{T}^{2}\right)$ & Normalised depth-averaged & $\theta$ & $(-)$ & Shields parameter \\
\hline & & dynamic pressure & $\theta_{c r}$ & $(-)$ & Critical Shields parameter \\
\hline$Q$ & $\left(\mathrm{~L}^{2}\right)$ & Sediment volume in RMSTE & $\kappa$ & $(-)$ & von Karman constant \\
\hline$q_{b}$ & $\left(\mathrm{~L}^{3} / \mathrm{L} / \mathrm{T}\right)$ & Sediment transport rate for bed load & $\lambda$ & (L) & Reference length scale \\
\hline$q_{s}$ & $\left(\mathrm{~L}^{3} / \mathrm{L} / \mathrm{T}\right)$ & $\begin{array}{l}\text { Sediment transport rate for } \\
\text { suspended load }\end{array}$ & $\begin{array}{l}v_{h} \\
\rho\end{array}$ & $\begin{array}{l}(-) \\
\left(\mathrm{M} / \mathrm{L}^{3}\right)\end{array}$ & $\begin{array}{l}\text { Horizontal viscosity } \\
\text { Water density }\end{array}$ \\
\hline $\begin{array}{l}q_{\text {sed }} \\
q_{\text {tot }}\end{array}$ & $\begin{array}{l}\left(\mathrm{L}^{3} / \mathrm{L} / \mathrm{T}\right) \\
\left(\mathrm{L}^{3} / \mathrm{L} / \mathrm{T}\right)\end{array}$ & $\begin{array}{l}\text { Instantaneous sediment transport rate } \\
\text { Total sediment transport rate }\end{array}$ & $\rho_{m r}$ & $(-)$ & $\begin{array}{l}\text { Pearson's cross-correlation } \\
\text { coefficient }\end{array}$ \\
\hline$q_{t o t, \text { mean }}$ & $\left(\mathrm{L}^{3} / \mathrm{L} / \mathrm{T}\right)$ & $\begin{array}{l}\text { Wave-averaged total sediment } \\
\text { transport rate }\end{array}$ & $\begin{array}{l}\rho_{s} \\
\tau_{b}\end{array}$ & $\begin{array}{l}\left(\mathrm{M} / \mathrm{L}^{3}\right) \\
\left(\mathrm{M} / \mathrm{L} / \mathrm{T}^{2}\right)\end{array}$ & $\begin{array}{l}\text { Sediment density } \\
\text { Total bed shear stress }\end{array}$ \\
\hline$R$ & $(-)$ & $\begin{array}{l}\text { Exponent in Pritchard and Hogg } \\
\text { (2003) }\end{array}$ & $\begin{array}{l}\tau_{b, c r} \\
\tau_{r e f}\end{array}$ & $\begin{array}{l}\left(\mathrm{M} / \mathrm{L} / \mathrm{T}^{2}\right) \\
\left(\mathrm{M} / \mathrm{L} / \mathrm{T}^{2}\right)\end{array}$ & $\begin{array}{l}\text { Critical bed shear stress } \\
\text { Reference bed shear stress }\end{array}$ \\
\hline$s_{y_{m}}$ & $(-)$ & $\begin{array}{l}\text { Standard deviation of the modelled } \\
\text { quantity }\end{array}$ & $\phi$ & $(-)$ & $\begin{array}{l}\text { Generic mathematical } \\
\text { function }\end{array}$ \\
\hline$s_{y_{r e f}}$ & $(-)$ & $\begin{array}{l}\text { Standard deviation of the reference } \\
\text { quantity }\end{array}$ & $\Omega$ & $(-)$ & $\begin{array}{l}\text { Dimensionless settling } \\
\text { velocity }\end{array}$ \\
\hline$S_{S l}$ & $(-)$ & Bed slope effects term & & & \\
\hline$t$ & $(\mathrm{~T})$ & Time & Abbreviations & & \\
\hline$t_{f}$ & $(\mathrm{~T})$ & Final time & ADV & & Acoustic Doppler Velocimeter \\
\hline$T_{g}$ & $(\mathrm{~T})$ & Wave group period & AWG & & Acoustic Wave Gauge \\
\hline$T_{p}$ & $(\mathrm{~T})$ & Mean primary wave period & $\mathrm{BBL}$ & & Bottom Boundary Layer \\
\hline$T_{r}$ & $(\mathrm{~T})$ & Repeat period & BE1_2 & & Broad-banded wave condition \\
\hline$T_{S}$ & $(\mathrm{~T})$ & Adaptation time & BE4_2 & & Narrow-banded wave condition \\
\hline$u$ & $(\mathrm{~L} / \mathrm{T})$ & Depth-averaged cross-shore velocity & $\mathrm{CCM}+$ & & Conducivity Concentration \\
\hline$u_{\text {mean }}$ & $(\mathrm{L} / \mathrm{T})$ & $\begin{array}{l}\text { Wave-averaged, depth-averaged } \\
\text { cross-shore velocity }\end{array}$ & $\mathrm{CN}$ & & $\begin{array}{l}\text { Measurements } \\
\text { Courant Number }\end{array}$ \\
\hline$u_{\text {ref }}$ & $(\mathrm{L} / \mathrm{T})$ & Reference scale velocity & HFA & & Hydrostatic Front \\
\hline$u_{r m s}$ & $(\mathrm{~L} / \mathrm{T})$ & Orbital wave velocity & & & Approximation \\
\hline$u_{*}$ & $(\mathrm{~L} / \mathrm{T})$ & Friction velocity & IWST & & Intra-Wave Sediment Transport \\
\hline$w_{s}$ & $(\mathrm{~L} / \mathrm{T})$ & Sediment settling velocity & MOC & & Method Of Characteristics \\
\hline$x$ & (L) & Cross-shore coordinate & NLSWE & & Non-Linear Shallow Water \\
\hline$x_{0}$ & (L) & $\begin{array}{l}\text { Model upstream boundary } \\
\text { cross-shore location }\end{array}$ & nRMSE & & $\begin{array}{l}\text { Equations } \\
\text { normalised Root-Mean-Square }\end{array}$ \\
\hline$y_{m}$ & $(-)$ & Modelled quantity & & & Error \\
\hline$y_{\text {ref }}$ & $(-)$ & Reference quantity & OBS & & OpticalBack-Scattering Sensor \\
\hline$z$ & (L) & Vertical coordinate & RMSTE & & Root-Mean-Square \\
\hline$z_{b}$ & (L) & Bed level & & & Transport Error \\
\hline$z_{b_{f}}$ & (L) & Final bed level & SEG & & Segment \\
\hline$z_{f, m}$ & $(\mathrm{~L})$ & Modelled final bed level in RMSTE & WG & & Wave Gauge \\
\hline$z_{b_{f, r e f}}$ & (L) & Reference final bed level in RMSTE & WAST & & Wave-Averaged \\
\hline$\alpha_{s l}$ & $(-)$ & $\begin{array}{l}\text { Calibration coefficient for } \\
\text { bed slope effects }\end{array}$ & XBNH & & $\begin{array}{l}\text { Sediment Transport } \\
\text { Non-Hydrostatic XBeach }\end{array}$ \\
\hline$\Delta$ & $(-)$ & Relative density & $1 \mathrm{D}$ & & One-dimensional \\
\hline
\end{tabular}


Acknowledgements This study is part of the doctoral thesis of Miss Giulia Mancini. Mr. Gioele Ruffini is acknowledged for providing numerical data for comparison with this study. Laboratory data were provided by Dr. Yin Lu Young and Dr. Heng Xiao for the consecutive non-interacting solitary waves.

Funding The experimental part of the bichromatic wave groups was funded by European Community's Seventh Framework Programme through the grant of the Integrating Activity HYDRALAB IV within the Transnational Access Activities; contract no. 261520.

Open Access This article is licensed under a Creative Commons Attribution 4.0 International License, which permits use, sharing, adaptation, distribution and reproduction in any medium or format, as long as you give appropriate credit to the original author(s) and the source, provide a link to the Creative Commons licence, and indicate if changes were made. The images or other third party material in this article are included in the article's Creative Commons licence, unless indicated otherwise in a credit line to the material. If material is not included in the article's Creative Commons licence and your intended use is not permitted by statutory regulation or exceeds the permitted use, you will need to obtain permission directly from the copyright holder. To view a copy of this licence, visit http:// creativecommonshorg/licenses/by/4.0/.

\section{Appendix 1: Sediment transport modelling in XBNH-WAST}

In XBNH-WAST, the advection equation for the sediment transport is formulated as:

$\frac{\partial h C}{\partial t}+\frac{\partial h u C}{\partial x}=\frac{h C_{e q}-h C}{T_{S}}=E-D$,

where $T_{s}$ is the adaptation time, which represents the entrainment of the sediment, depending on $h$ and $w_{s}$, and $C_{e q}$ is the total equilibrium sediment concentration. XBNHWAST calculates the equilibrium concentration using the the Van Rijn et al. (2007), Van Thiel de Vries (2008) formulations. For both the bed load and the suspended load, referred to as $b$ and $s$, respectively, the equilibrium concentrations are expressed in function (“ $\phi$ ”) of $u$ and the wave orbital velocity, $u_{r m s}$, as:

$C_{e q, b, s}=A_{b, s} \phi\left(u, u_{r m s}\right)$,

where $A_{b, s}$ represents, alternatively, the bed load and suspended load coefficients, depending on sediments' grain size and flow properties. The Van Rijn et al. (2007) and Van Thiel de Vries (2008) sediment transport formulations were originally developed for the wave-averaged version of XBeach, where $u$ represents the wave-averaged crossshore flow velocity, computed by means of NLSWE, and $u_{r m s}$ is computed as a parameterisation of the short-wave energy (Roelvink et al. 2009). XBNH solves the intra-wave flow through the extended NLSWE, and the total intra-wave cross-shore velocity is included in the term " $u$." Consequently, in XBNH-WAST, the term " $u_{r m s}$ " in Eq. (22) is equal to 0 . For a more detailed implementation of XBNHWAST, the reader is referred to Deltares (2015).

\section{Appendix 2: Comparison of XBH-IWST and Zhu and Dodd (2015) for the hydrodynamics}

Figure 17 shows the time series of $h$ and the scaled velocity, $u / \sqrt{g \lambda}$, at two different cross-shore locations. Overall, results show a very good agreement in terms of

Table 10 nRMSE and $\rho_{m r}$ for $h$ and $u / \sqrt{g \lambda}$ at two different crossshore locations

\begin{tabular}{|c|c|c|c|c|}
\hline & \multicolumn{2}{|c|}{ nRMSE } & \multicolumn{2}{|l|}{$\rho_{\mathrm{mr}}$} \\
\hline & $h$ & $u / \sqrt{g \lambda}$ & $h$ & $u / \sqrt{g \lambda}$ \\
\hline$x=-10 \mathrm{~m}$ & 0.2078 & 0.1382 & 0.9881 & 0.9915 \\
\hline$x=0 \mathrm{~m}$ & 0.2576 & 0.1684 & 0.9794 & 0.9860 \\
\hline
\end{tabular}

Fig. 17 Time series of $h$ at $x=-10 \mathrm{~m}$ a and $x=0 \mathrm{~m} \mathrm{~b}$, and $u / \sqrt{g \lambda}$ at $x=-10 \mathrm{~m} \mathbf{c}$ and $x=0 \mathrm{~m} \mathrm{~d}$; reference line: grey dashed line; the two subplots in $\mathbf{a}$ and $\mathbf{b}$ show the two cross-shore locations in the model domain, respectively a

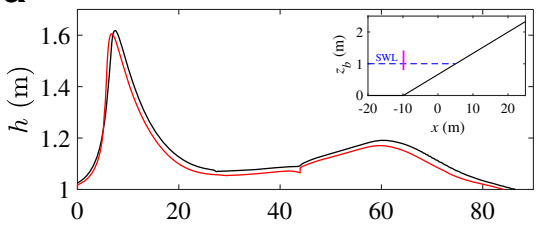

C

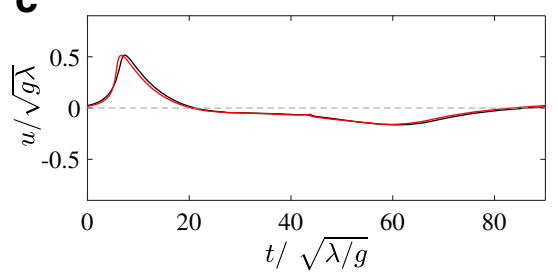

b

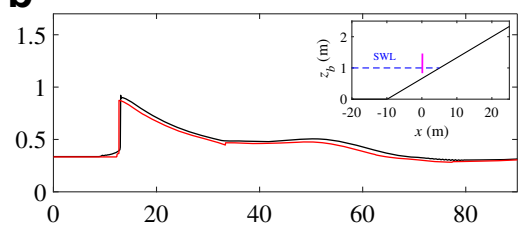

d

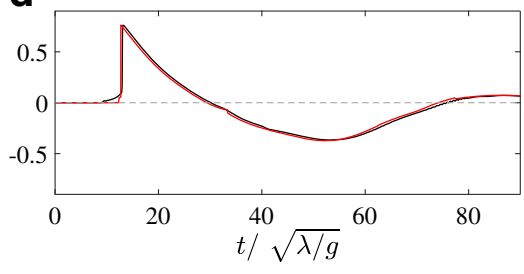

XBH-IWST — Zhu and Dodd (2015) 
hydrodynamics response between XBH-IWST and Zhu and Dodd (2015) (see also Table 10).

\section{Appendix 3: Representation of the net return flow in XBNH-IWST}

Since $\mathrm{XBNH}$ is based on the one-layer version of the SWASH model, no vertical discretisation of the velocity profile is available. Therefore, only a depth- and phaseaveraged net current can be obtained from the model. Results show that the predicted net current is directed offshore. Figure 18 shows the modelled and experimental $u$ for SEG1 of BE1 2 for the Alsina et al. (2016) case and the wave-averaged velocity over the wave group period, $T_{g}=15 \mathrm{~s}, u_{\text {mean }} ; u_{\text {mean }}=-0.46 \mathrm{~m} / \mathrm{s}$ for XBNH-IWST and $u_{\text {mean }}=-0.48 \mathrm{~m} / \mathrm{s}$ for the experiments. Figure 18 also shows the modelled $q_{t o t}=q_{s}+q_{b}$ for the same segment. $q_{t o t}$ is also depth-averaged, and the presence of a net depth-averaged velocity leads to net mean offshore transport, $q_{\text {tot, } \text { mean }}=-0.001 \mathrm{~m}^{3} / \mathrm{m} / \mathrm{s}$, even if entrainment is considered.

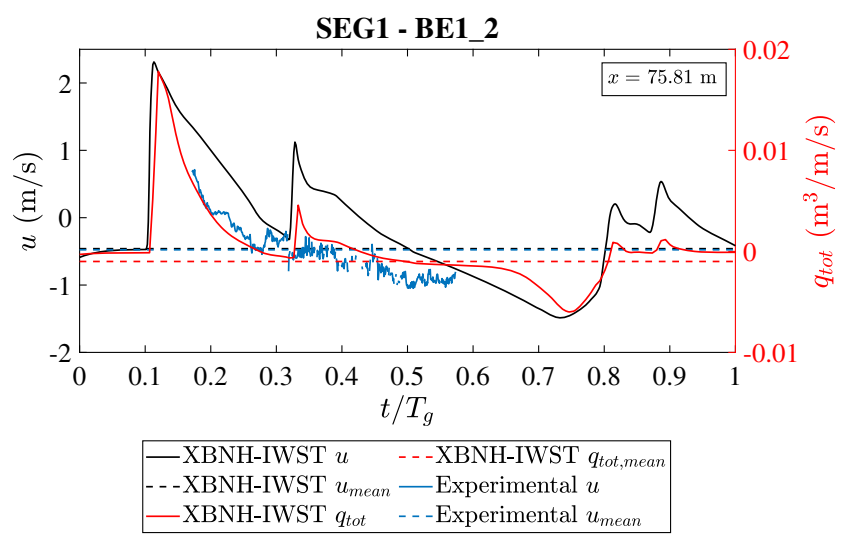

Fig. 18 Time series of $u$ and $q_{\text {tot }}$, and $u_{\text {mean }}$ and $q_{\text {tot,mean }}$ at $x=75.81$ m over $T_{g}$ for SEG1 of BE1_2 (Alsina et al. 2016)

\section{References}

Alsina JM, Cáceres I, Brocchini M, Baldock TE (2012) An experimental study on sediment transport and bed evolution under different swash zone morphological conditions. Coast Eng 68:31-43

Alsina JM, Falchetti S, Baldock TE (2009) Measurements and modelling of the advection of suspended sediment in the swash zone by solitary waves. Coast Eng 56(5-6):621-631

Alsina JM, Padilla EM, Cáceres I (2016) Sediment transport and beach profile evolution induced by bi-chromatic wave groups with different group periods. Coast Eng 114:325-340

Alsina JM, Van der Zanden J, Caceres I, Ribberink JS (2018) The influence of wave groups and wave-swash interactions on sediment transport and bed evolution in the swash zone. Coastal Engineering 140:23-42
Bai Y, Yamazaki Y, FaiCheung K (2018) Convergence of multilayer nonhydrostatic models in relation to Boussinesq-type equations. $\mathrm{J}$ Waterw Port Coast Ocean Eng 144(2):06018001

Bosboom J, Mol M, Reniers AJHM, Stive MJF, deValk CF (2020) Optimal sediment transport for morphodynamic model validation. Coast Eng 158:103662

Briganti R, Dodd N, Kelly D, Pokrajac D (2012) An efficient and flexible solver for the simulation of the morphodynamics of fast evolving flows on coarse sediment beaches. Int J Numer Methods Fluids 69(4):859-877

Briganti R, Dodd N, Incelli G, Kikkert G (2018) Numerical modelling of the flow and bed evolution of a single bore-driven swash event on a coarse sand beach. Coast Eng 142:62-76

Briganti R, Dodd N, Pokrajac D, O’Donoghue T (2011) Non linear shallow water modelling of bore-driven swash: Description of the bottom boundary layer. Coast Eng 58(6):463-477

Briganti R, Torres-Freyermuth A, Baldock TE, Brocchini M, Dodd N, Hsu T-J, Jiang Z, Kim Y, Pintado-Patiño JC, Postacchini M (2016) Advances in numerical modelling of swash zone dynamics. Coast Eng 115:26-41

Brocchini M, Baldock TE (2008) Recent advances in modeling swash zone dynamics: Influence of surf-swash interaction on nearshore hydrodynamics and morphodynamics. Rev Geophys 46(3):RG3003

Chardón-Maldonado P, Pintado-Patiño JC, Puleo JA (2016) Advances in swash-zone research: Small-scale hydrodynamic and sediment transport processes. Coastal Engineering 115:8-25

Deltares (2015) XBeach documentation, <https://xbeach.readthedocs. io>

Gourlay MR, Meulen T (1968) Beach and dune erosion tests. Proceedings of the 11th Conference on Coastal Engineering, London 1:701-707

Incelli G, Dodd N, Blenkinsopp CE, Zhu F, Briganti R (2016) Morphodynamical modelling of field-scale swash events. Coast Eng 115:42-57

Kim D-H, Sanchez-Arcilla A, Caceres I (2017) Depth-integrated modelling on onshore and offshore sandbar migration: Revision of fall velocity. Ocean Model 110:21-31

Li L, Barry DA, Pattiaratchi CB, Masselink G (2002) Beachwin: modelling groundwater effects on swash sediment transport and beach profile changes. Environmental Modelling \& Software 17(3):313-320

Ma G, Shi F, Kirby JT (2012) Shock-capturing non-hydrostatic model for fully dispersive surface wave processes. Ocean Model 43:2235

Masselink G, Gehrels R (2014) Coastal environments and global change. John Wiley \& Sons, New Jersey, pp 149-177

Masselink G, Puleo JA (2006) Swash-zone morphodynamics. Cont Shelf Res 26(5):661-680

McCall RT (2015) Process-based modelling of storm impacts on gravel coasts. Ph.D. Thesis, Plymouth University

McCall RT, Masselink G, Poate TG, Roelvink JA, Almeida LP (2015) Modelling the morphodynamics of gravel beaches during storms with XBeach-G. Coast Eng 103:52-66

McCormack R (1969) The effect of viscosity in hypervelocity impact cratering. AIAA Hyper Velocity Impact Conference, 69-354

Mei CC (1989) The applied dynamics of ocean surface waves. World scientific

Meyer-Peter E, Müller R (1948) Formulas for bed-load transport. In: IAHSR 2nd meeting, Stockholm, appendix 2. IAHR

Postacchini M, Brocchini M, Mancinelli A, Landon M (2012) A multipurpose, intra-wave, shallow water hydro-morphodynamic solver. Adv Water Resour 38:13-26 
Pritchard D, Hogg AJ (2003) Suspended sediment transport under seiches in circular and elliptical basins. Coast Eng 49(1-2):43-70

Reniers AJHM, Gallagher EL, MacMahan JH, Brown JA, VanRooijen AA, deVries JSMvanThiel, VanProoijen BC (2013) Observations and modeling of steep-beach grain-size variability. Journal of Geophysical Research: Oceans 118(2):577-591

Rijnsdorp DP, Smit PB, Zijlema M, Reniers AdJHM (2017) Efficient non-hydrostatic modelling of $3 \mathrm{~d}$ wave-induced currents using a subgrid approach. Ocean Model 116:118-133

Roelvink D, McCall R, Mehvar S, Nederhoff K, Dastgheib A (2018) Improving predictions of swash dynamics in XBeach: The role of groupiness and incident-band runup. Coast Eng 134:103-123

Roelvink D, Reniers A, Van Dongeren AP, de Vries JT, McCall R, Lescinski J (2009) Modelling storm impacts on beaches, dunes and barrier islands. Coast Eng 56(11):1133-1152

Ruffini G, Briganti R, Alsina J, Brocchini M, Dodd N, McCall $\mathrm{R}$ (2020) Numerical modelling of flow and bed evolution of bichromatic wave groups on an intermediate beach using non-hydrostatic XBeach. J Waterw Port Coast Ocean Eng 146(1):04019034

Smit PB, Stelling GS, Roelvink D, van Thielde Vries JSM, McCall RT, van Dongeren AR, Zwinkels C, Jacobs R (2010) XBeach: Nonhydrostatic model. Delft University of Technology and Deltares

Smit P, Zijlema M, Stelling G (2013) Depth-induced wave breaking in a non-hydrostatic, near-shore wave model. Coast Eng 76:1-16

Soulsby R (1997) Dynamics of marine sands: a manual for practical applications. Thomas Telford, London

Sumer BM, Jensen BL, Fredsøe J (1987) Turbulence in oscillatory boundary layers. In: Advances in turbulence, pp 556-567. Springer
Titov VV, Synolakis CE (1995) Modeling of breaking and nonbreaking long-wave evolution and runup using vtcs-2. J Waterw Port Coast Ocean Eng 121(6):308-316

Van Rijn L, Ruessink G, Grasmeijer B, Van der Werf J, Ribberink J (2007) Wave-related transport and nearshore morphology. In: Coastal Sediments' 07, pp 1-14

Van Rijn LC (2007) Unified view of sediment transport by currents and waves. i: Initiation of motion, bed roughness, and bed-load transport. J Hydraul Eng 133(6):649-667

Van Thiel de Vries JSM (2008) Dune erosion during storm surges. $\mathrm{Ph} . \mathrm{D}$. Thesis, Technical University of Delft

Wenneker I, van Dongeren A, Lescinski J, Roelvink D, Borsboom M (2011) A boussinesq-type wave driver for a morphodynamical model to predict short-term morphology. Coast Eng 58(1):66-84

Wong PP, Losada IJ, Gattuso J-P, Hinkel J, Khattabi A, McInnes KL, Saito Y, Sallenger A et al (2014) Coastal systems and low-lying areas. Climate change 2104:361-409

Xiao H, Young YL, Prévost JH (2010) Hydro-and morpho-dynamic modeling of breaking solitary waves over a fine sand beach. part ii: Numerical simulation. Mar Geol 269(3-4):119-131

Young YL, Xiao H, Maddux T (2010) Hydro-and morpho-dynamic modeling of breaking solitary waves over a fine sand beach. part $\mathrm{i}$ : Experimental study. Mar Geol 269(3-4):107-118

Zhang Q, Liu PL-F (2008) A numerical study of swash flows generated by bores. Coast Eng 55(12):1113-1134

Zhu F, Dodd N (2015) The morphodynamics of a swash event on an erodible beach. J Fluid Mech 762:110-140

Zijlema M, Stelling G, Smit P (2011) Swash: an operational public domain code for simulating wave fields and rapidly varied flows in coastal waters. Coast Eng 58(10):992-1012 